\title{
Initiating molecular growth in the interstellar medium via dimeric complexes of observed ions and molecules ${ }^{\star}$
}

\author{
Partha P. Bera ${ }^{1}$, Martin Head-Gordon ${ }^{2}$, and Timothy J. Lee ${ }^{3, \star \star}$
}

\author{
${ }^{1}$ MS: 245-6, Space Science and Astrobiology Division, NASA Ames Research Center, Mountain View, 94035 California, USA \\ e-mail: partha.p.bera@nasa.gov \\ 2 Department of Chemistry, University of California and Chemical Sciences Division, Lawrence Berkeley National Laboratory, \\ Berkeley, 94720 California, USA \\ 3 MS: 245-1, Space Science and Astrobiology Division, NASA Ames Research Center, Mountain View, 94035 California, USA
}

Received 19 April 2011 / Accepted 18 July 2011

\begin{abstract}
A feasible initiation step for particle growth in the interstellar medium (ISM) is simulated by means of ab initio quantum chemistry methods. The systems studied are dimer ions formed by pairing nitrogen containing small molecules known to exist in the ISM with ions of unsaturated hydrocarbons or vice versa. Complexation energies, structures of ensuing complexes and electronic excitation spectra of the encounter complexes are estimated using various quantum chemistry methods. Møller-Plesset perturbation theory (MP2), Z-averaged perturbation theory (ZAPT2), coupled cluster singles and doubles with perturbative triples corrections $(\operatorname{CCSD}(\mathrm{T}))$, and density functional theory (DFT) methods (B3LYP) were employed along with the correlation consistent cc-pVTZ and aug-cc-pVTZ basis sets. Two types of complexes are predicted. One type of complex has electrostatic binding with moderate (7-20 kcal mol${ }^{-1}$ ) binding energies, that are nonetheless significantly stronger than typical van der Waals interactions between molecules of this size. The other type of complex develops strong covalent bonds between the fragments. Cyclic isomers of the nitrogen containing complexes are produced very easily by ion-molecule reactions. Some of these complexes show intense ultravioletvisible spectra for electronic transitions with large oscillator strengths at the B3LYP, $\omega \mathrm{B} 97$, and equations of motion coupled cluster (EOM-CCSD) levels. The open shell nitrogen containing carbonaceous complexes especially exhibit a large oscillator strength electronic transition in the visible region of the electromagnetic spectrum.
\end{abstract}

Key words. astrochemistry - acceleration of particles - molecular processes

\section{Introduction}

In the interstellar medium (ISM) thus far, inorganic salts, neutral hydrocarbons, olefins, cumulenes, nitriles, alcohols, carboxylic acids, cations, and anions have been identified (Gerakins 2011). Some of these are in the gas phase, and some are in interstellar ices and grains. Large polycyclic aromatic hydrocarbons (PAH) are also known to exist in the ISM, as a general class of interstellar molecules (Chillier et al. 1999; Salama et al. 1999). Recently, two fullerene molecules (C60 and C70) have been identified in a carbon rich planetary nebulae (Cami et al. 2010). It is proposed that the identification of individual PAH molecules could help to resolve some of the mysteries associated with the diffuse interstellar bands (DIBs; Salama et al. 1999; Snow 2001) and the galactic extended red emission (ERE; Rhee et al. 2007). Similar to PAHs, spectroscopic signatures of nitrogen containing polycyclic aromatic hydrocarbons (PANH) are prevalent in various cosmological environments (Hudgins et al. 2005). Nitrogen containing molecules and ions have been observed throughout the ISM. Gas phase reactions of nitrogen containing species with carbonaceous compounds represent an ideal way to incorporate nitrogen into carbon chain growth, and ultimately into cyclic and polycyclic carbon compounds. Although the smaller molecules

\footnotetext{
* Appendix A is available in electronic form at

http: //www . aanda.org

$\star \star$ Corresponding author email: Timothy. J . Lee@nasa.gov
}

are pervasive in the ISM, how large molecules, chains, polycyclic complexes, and grains are formed in the ISM remains an open question.

Weak intermolecular interactions dipole-dipole, ion-induced dipole, hydrogen bonding, and dispersion (van der Waals) forces between atoms, molecules, and ions, play major roles in nature. For example, in biological systems hydrogen bonding helps to keep a whole DNA strand together. In the gas phase, long-range ion-dipole and electrostatic interactions guide species to come together to form aggregates. In the very low particle density cold ISM, in the absence of other strong forces, these weak interactions can guide ions and molecules to condense into aggregates and initiate reactions (Herbst 2001; Smith 2002). Ions are relatively abundant species in the strong radiation fields of the ISM, in star forming regions, in planetary nebulae, and in boundary regions between hot and cold environments. Ion-molecule reactions are barrierless and spontaneous in the gas phase. It is reasonable, therefore, to ask if this cold condensation can be a viable mechanism for forming small molecular complexes, large PAHs, and grains? And, if so, what are the specific pathways?

Earlier theoretical and experimental studies have concentrated on the $\pi-\pi$ interactions leading to stable complexes in alkenes (Bates et al. 2008; Hopkins \& Tschumper 2004), aromatic systems (Sinnokrot \& Sherrill 2004), and even in PAHs (Hirata et al. 1999; Szczepanski \& Vala 1993; Weisman et al. 2001; Weisman et al. 2005). The neutral complexes are typically 
bound by van der Waals interactions (though aromatic radicalradical stacking complexes with partial covalent character are known (e.g., Small et al. 2005). However, the cationic complexes are bound by both electrostatic and covalent interactions. Closed and open shell PAH dimers are estimated to be bound by energies of about $20 \mathrm{kcal} \mathrm{mol}^{-1}$, and absorb in the visible and sometimes in the infrared (Rhee et al. 2007; Weisman et al. 2005). The cationic complexes of small olefins, especially the nitrogen containing ones, have not been explored in any detail.

The objective of the current study is threefold. Firstly, we have examined, by means of ab initio quantum chemical methods, the nature of binding among the simplest complexes between some observed interstellar molecules and ions. In other words, the question of how the small precursors complex together to form larger aggregates in interstellar low-density, low temperature conditions is explored. Secondly, we have computed the UV-Vis electronic spectra and the vibrational spectra of these species so that they may be compared with experiments as well as existing astronomical observations. It is vital to know the structural and spectroscopic nature of the ensuing complexes to understand their formation pathways. Some of these ion complexes may have large oscillator strengths in their electronic spectra due to charge transfer excitations. Thirdly, we have performed a systematic study of the complexes using various ab initio quantum chemistry methods. Binding energies, excitation energies and geometrical parameters obtained using affordable density functional and perturbation theory methods were compared and benchmarked with results obtained by highly accurate coupled cluster methods. This benchmarking study will help us choose more affordable ab initio quantum chemistry methods for charting out pathways of formation of larger molecules in the future where coupled cluster calculations may not be computationally feasible.

Several studies have examined the radiative association reaction rates for relatively simple cation/neutral reactions such as $\mathrm{C}^{+}+\mathrm{H}_{2}$, and even up to systems with three heavy (nonhydrogen) atoms under ISM conditions (Black et al. 1975; Smith 1992; Gerlich \& Horning 1992; Barinovs \& van Hemert 2006; Herbst et al. 2010). While our study is related to these investigations, examining formation products and their spectroscopic signatures, we have not investigated the radiative association rates, though we note that the studies cited above have demonstrated that in general radiative association rates increase as the cations/neutrals increase in size, which of course is consistent with the larger number of rovibrational degrees of freedom.

\section{Theoretical methods}

The geometrical structures reported in this research are optimized using second order Møller-Plesset perturbation theory (MP2) along with Dunnings correlation consistent polarized valence triple zeta basis set (cc-pVTZ) and the augmented correlation consistent polarized valence triple zeta basis set (aug-cc-pVTZ; Dunning 1989). MP2/aug-cc-pVTZ optimized geometries were used when calculating the binding energies of the complexes employing the coupled cluster singles and doubles with a perturbative triples correction, $\operatorname{CCSD}(\mathrm{T})$, method (Purvis \& Bartlett 1982; Raghavachari et al. 1989; Lee \& Scuseria 1995), in conjunction with the cc-pVTZ and aug-ccpVTZ basis sets. The binding energies were calculated by subtracting the absolute energies of the neutral and the cationic fragments from the energy of the cationic bound complex. Binding energies were also determined using a density functional theory (DFT) method for comparison. We employ Becke's widely used three-parameter hybrid functional (Becke 1993), based on the Becke exchange functional (Becke 1988) paired up with the correlation functional of Lee et al. (LYP; Lee et al. 1988). All geometries were fully optimized using B3LYP along with the cc-pVTZ basis set. A fine grid of 75 radial points and 590 angular functions was used for all the DFT computations. Open shell molecules were treated with unrestricted MP2 (UMP2), second order Z-averaged perturbation theory (ZAPT2) (Lee \& Jayatilaka 1993; Lee et al. 1994), and UB3LYP methods along with the cc-pVTZ basis set. The ZAPT2 method is based on the use of a symmetric spin orbital basis (Jayatilaka \& Lee 1992), and leads to $S_{x}$ eigenfunctions in the $n$-particle space. It has been shown to have less spin contamination relative to UMP2 and other restricted open-shell perturbation theories, and to have a larger radius of convergence, and to be less costly (computationally) as well (Lee et al. 1994). For electronic excitation energies, starting from the ground electronic state to various singlet excited states, including oscillator strengths, time dependent density functional theory (TDDFT) (Hirata et al. 1999) computations were carried out using the B3LYP density functional and the cc-pVTZ basis set. A range separated density functional, $\omega \mathrm{B} 97$ (Chai \& Head-Gordon 2008), that is specifically designed for weak interactions was also employed. For valence electronic transitions TDDFT has been shown to work well (Hirata et al. 1999; Weisman et al. 2001; Halasinski et al. 2003; Hirata et al. 2003). The range-separated functional, $\omega \mathrm{B} 97$, significantly reduces the serious problems of TDDFT with conventional functionals for charge-transfer excited states (Dreuw \& Head-Gordon 2004). The Q-Chem3.1 (Shao et al. 2006) ab initio quantum chemistry code was used for all the DFT, TDDFT, MP2, (and UMP2) and ZAPT2 computations. Coupled cluster calculations were carried out using the MOLPRO 2006 (Werner \& Knowels 2006) quantum chemistry package. Harmonic vibrational frequency calculations were carried out at the MP2/cc-pVTZ and MP2/aug-cc-pVTZ levels to ensure that the molecules and complexes presented here represent true minima. The Cartesian coordinates of all the species discussed in this work are included in the supplementary material available with the web site.

\section{Results}

Elementary growth processes starting from some of the nitrogen containing molecules or ions observed in interstellar space are investigated in the following sections. Specifically, several nitrogen containing interstellar molecules and cations that have been observed in the ISM were paired up with small, unsaturated hydrocarbons to simulate the initial nucleation step that could then be a pathway to formation of larger molecules, such as PAHs and PANHs, and ultimately to grain formation. Cationic complex formation is guided by long-range weak electrostatic iondipole type attraction, in which a wide variety of exotic products are expected. Some ion-molecule reactions in the low temperature and ultra low-density conditions of the ISM readily make strong covalent bonds to produce linear or branched chains, replication of which leads to chain growth. In the next section we will see that these types of reactions take place with significant favorable energy changes for larger molecule formation. Other dimers make relatively weak and chemically interesting face-to-face $\pi$-stacked or T-shaped complexes bound by electrostatic or ion-dipole type interactions. Although several association or encounter complexes are investigated in depth for each system, only the simplest kinds of encounter complexes are included in this work as it is not intended to be an extensive search 
P. P. Bera et al.: Initiating molecular growth in the ISM

Table 1. Binding energies (in $\mathrm{kcal} \mathrm{mol}^{-1}$ ) of the dimer cations between (mostly) known interstellar molecules and cations are listed.

\begin{tabular}{|c|c|c|c|c|c|c|}
\hline Figure & Reaction/Complex & $\overline{\text { B3LYP/cc-pVTZ }}$ & MP2/cc-pVTZ & "MP2/aug-cc-pVTZ & CCSD(T)/cc-pVTZ & 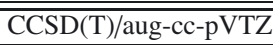 \\
\hline Fig. 1.A & $\mathrm{C}_{2} \mathrm{H}_{4}+\mathrm{HCNH}^{+} \rightarrow\left[\mathrm{C}_{2} \mathrm{H}_{4}: \mathrm{HCNH}\right]^{+}$ & 11.52 & 11.97 & 13.25 & 11.25 & 11.7 \\
\hline Fig. $1 . B$ & $\mathrm{C}_{2} \mathrm{H}_{4}+\mathrm{HCNH}^{+} \rightarrow\left[\mathrm{C}_{2} \mathrm{H}_{4}: \mathrm{HNCH}\right]^{+}$ & 16.34 & 17.92 & 19.71 & 16.05 & 16.58 \\
\hline Fig. 1.C & $\mathrm{C}_{2} \mathrm{H}_{4}+\mathrm{HCNH}^{+} \rightarrow\left[\mathrm{C}_{2} \mathrm{H}_{4}: \mathrm{HCNH}\right]^{+}$, Boat & 48.28 & 50.88 & 52.2 & 49.47 & 50.07 \\
\hline Fig. 1.D & $\mathrm{C}_{2} \mathrm{H}_{4}+\mathrm{HCNH}^{+} \rightarrow\left[\mathrm{C}_{2} \mathrm{H}_{4}: \mathrm{HCNH}\right]^{+}$, Bridge & 7.88 & 1.66 & 3.16 & 1.82 & 1.96 \\
\hline Fig. 2.A & $\mathrm{C}_{2} \mathrm{H}_{4}+\mathrm{H}_{2} \mathrm{CNH}_{2}^{+} \rightarrow\left[\mathrm{C}_{2} \mathrm{H}_{4}: \mathrm{H}_{2} \mathrm{CNH}_{2}\right]^{+}$ & 8.16 & 8.3 & 9.36 & 6.89 & 7.7 \\
\hline Fig. $2 . B$ & $\mathrm{C}_{2} \mathrm{H}_{4}+\mathrm{H}_{2} \mathrm{CNH}_{2}^{+} \rightarrow\left[\mathrm{C}_{2} \mathrm{H}_{4}: \mathrm{H}_{2} \mathrm{CNH}_{2}\right]^{+}$, Boat & 26.00 & 36.11 & 38.85 & 31.1 & 32.01 \\
\hline Fig. 3.A & $\mathrm{HCCH}+\mathrm{HCNH}^{+} \rightarrow[\mathrm{HCCH}: \mathrm{HCNH}]^{+}$ & 11.49 & 8.51 & 12.56 & 11.06 & 11.53 \\
\hline Fig. 3.B & $\mathrm{HCCH}+\mathrm{HCNH}^{+} \rightarrow[\mathrm{HCCH}: \mathrm{HCNH}]^{+}$ & 15.93 & 10.62 & 18.49 & 15.55 & 16.08 \\
\hline Fig. 3.C & $\mathrm{HCCH}+\mathrm{HCNH}^{+} \rightarrow[\mathrm{HCCH}: \mathrm{HCNH}]^{+}$, Boat & 19.13 & 15.7 & 16.68 & 20.28 & 20.75 \\
\hline Fig. 4 & $\mathrm{HCN}+\mathrm{C}_{2} \mathrm{H}_{3}^{+} \rightarrow\left[\mathrm{HCN}: \mathrm{C}_{2} \mathrm{H}_{3}\right]^{+}$ & 72.01 & 66.2 & 71.57 & 68.81 & 68.38 \\
\hline Fig. 5.A & $\mathrm{HCC}^{+}+\mathrm{HCN} \rightarrow \mathrm{HCCHCN}$, Branched & 125.93 & 125.62 & 134.41 & 154.13 & 154.3 \\
\hline Fig. 5.B & $\mathrm{HCC}^{+}+\mathrm{NCH} \rightarrow[\mathrm{HCCNCH}]^{+}$, Linear & 180.73 & 181.66 & 198.26 & 205.52 & 205.6 \\
\hline Fig. 6.A & $\mathrm{HCCC}^{+}+\mathrm{HCN} \rightarrow[\mathrm{HCCC}(\mathrm{H}) \mathrm{CN}]^{+}$, Branched & 42.09 & 38.25 & 40.42 & 38.48 & 38.7 \\
\hline Fig. $6 . B$ & $\mathrm{HCCC}^{+}+\mathrm{HCN} \rightarrow[\mathrm{HCCCNCH}]^{+}$, Linear & 59.92 & 53.12 & 55.03 & 48.44 & 48.81 \\
\hline
\end{tabular}

Table 2. Binding energies (in $\mathrm{kcal} \mathrm{mol}^{-1}$ ) of the open shell complexes of astrochemically observed species.

\begin{tabular}{|c|c|c|c|c|c|c|}
\hline Figure & Reaction/Complex & B3LYP/cc-pVTZ & UMP2/cc-pVTZ & UMP2/aug-cc-pVTZ & ZAPT2/cc-pVTZ & $\operatorname{CCSD}(\mathrm{T}) / \mathrm{cc}-\mathrm{pVTZ}$ \\
\hline Fig. 7 & $\mathrm{H}_{2} \mathrm{CCH}_{2}+\mathrm{H}_{2} \mathrm{CNH}^{+} \rightarrow\left[\mathrm{H}_{2} \mathrm{CCH}_{2}: \mathrm{H}_{2} \mathrm{CNH}\right]^{+}$ & 17.31 & 10.15 & 11.25 & 9.44 & 10.28 \\
\hline Fig. 8.A & $\mathrm{H}_{2} \mathrm{CNH}_{2}+\mathrm{H}_{2} \mathrm{CNH}_{2}^{+} \rightarrow\left[\mathrm{H}_{2} \mathrm{CNH}_{2}\right]_{2}^{+}$, Pi-stack & 25.49 & 22.84 & 22.64 & 23.71 & 24.98 \\
\hline Fig. 8.B & $\mathrm{H}_{2} \mathrm{CNH}_{2}+\mathrm{H}_{2} \mathrm{CNH}_{2}^{-} \rightarrow\left[\mathrm{H}_{2} \mathrm{CNH}_{2}\right]_{2}^{+}$, Trans & 35.76 & 37.95 & 38.42 & 39.22 & 40.2 \\
\hline
\end{tabular}

of the entire potential energy surfaces for all possible minima of the molecular complexes. That is, complex or molecule formation in which a significant potential barrier must be overcome are not investigated in the present study. Binding energies for closed-shell complexes are presented in Table 1 and similarly for open-shell complexes in Table 2. In Tables 3 and 4, the electronic excitation energies are presented at the B3LYP/cc-pVTZ and $\omega$ B97/cc-pVTZ levels of theories. In Table 3, the excitation energies of the complexes are given, while in Table 4 those of the monomeric molecules and ions are listed. While this paper is focused on nitrogen containing complexes, we have additionally studied the pure carbon complexes of $\mathrm{HCCH}, \mathrm{H}_{2} \mathrm{CCH}_{2}$ with their cations, which will be presented in another paper (Bera et al., in prep.).

\subsection{Closed shell cation}

I. $\left[\mathrm{C}_{2} \mathrm{H}_{4}-\mathrm{HCNH}\right]^{+}$. Ethylene, hydrogen cyanide and protonated hydrogen cyanides are observed species in some carbonaceous interstellar clouds (Snyder \& Buhl 1971; Ziurys \& Turner 1986). Electrostatic interaction between protonated hydrogen cyanide and ethylene leads to two $\mathrm{C}_{2 v}$ symmetry stable T-shaped complexes and two cyclic isomers with favorable binding energies. The $\mathrm{CH}$ hydrogen in $\mathrm{HCNH}^{+}$interacts with the $\pi$ electron clouds of $\mathrm{H}_{2} \mathrm{CCH}_{2}$ to make the stable complex A presented in Fig. 1.A. The distance between the $\mathrm{H}$ atom and either of the $\mathrm{C}$ atoms of ethylene is 2.156, and the binding energy is $13.24 \mathrm{kcal} \mathrm{mol}^{-1}$ at the geometry optimized at the MP2/aug-ccpVTZ level of theory. As shown in Table 1, the binding energy at the higher CCSD(T)/aug-cc-pVTZ//MP2/aug-cc-pVTZ level of theory is $11.7 \mathrm{kcal} \mathrm{mol}^{-1}$ (henceforth we will abbreviate this as the CCSD(T)/aug-cc-pVTZ binding energy). The NH hydrogen in $\mathrm{HCNH}^{+}$also interacts favorably with ethylene to make a more stable isomer, B, of this complex, presented in Fig. 1.B. The NH-C distance is 1.912 at the MP2/aug-cc-pVTZ optimized geometry. The more tightly bound nature of the complex is reflected in the larger binding energy, $16.58 \mathrm{kcal} \mathrm{mol}^{-1}$ at the CCSD(T)/aug-cc-pVTZ level, as presented in Table 1.
Although, formation of the lower energy isomer is expected due to thermodynamic reasons, the branching ratio for formation of the two isomers will depend on the approach geometries of the two constituents, and their relative translational energy. The apparent branching ratio may also depend upon the barrier to internal conversion between the isomers.

The electronic excitation energies (in $\mathrm{eV}$ ) and oscillator strengths are presented in Table 3 for all the complexes calculated using TDDFT as stated previously. Both have very strong oscillator strength absorption features in the UV. As seen from Table 3, B3LYP under predicts the excitation energies of these weakly bound complexes compared to the $\omega \mathrm{B} 97$ functional, which reduces self-interaction errors. The $\omega \mathrm{B} 97$ results $(5.56 \mathrm{eV})$ are much closer to the excitation energies obtained at the EOM-CCSD/cc-pVTZ level of theory $(6.46 \mathrm{eV})$ for the complex 1A. For complex 1B the EOM-CCSD excitation energy for the first excited state is $7.22 \mathrm{eV}$ compared to $6.57 \mathrm{eV}$ obtained with the $\omega \mathrm{B} 97$ functional.

Two other isomers with more traditional covalent bonding features are also located on the potential energy surface of the association complex. These are a four-membered ring and a three-membered ring structure. The four-membered ring isomer presented in Fig. 1.C is bound by $50.07 \mathrm{kcal} \mathrm{mol}^{-1}$ energy at the CCSD(T)/aug-cc-pVTZ level, making it the most strongly bound of the isomers studied. By contrast, however, the threemembered ring structure (D) is the most weakly bound of the structures presented in Fig. 1.D, with only $1.82 \mathrm{kcal} \mathrm{mol}^{-1}$ of binding energy. A comparison of the association energies for the complexes using the B3LYP, MP2 and CCSD(T) methods is presented in Table 1. Both B3LYP and MP2 estimated association energies match very well in comparison to $\operatorname{CCSD}(\mathrm{T})$. The boat (Fig. 1.C) and the bridge (Fig. 1.D) isomers have intense electronic absorptions at $7.99 \mathrm{eV}$ and $8.54 \mathrm{eV}$ respectively.

Association energies for a complex between an ionic and a neutral species are generally large and thus are not going to be significantly changed by the basis set superposition error (BSSE) correction. One possible exception is the case of the bridge structure (Fig. 1.D) for which the association energy is small 
Table 3. TDDFT electronic excitation energies (in eV) of the complexes calculated with B3LYP/cc-pVTZ and $\omega$ B97/cc-pVTZ.

\begin{tabular}{|c|c|c|c|c|c|c|c|c|c|c|c|}
\hline \multirow[b]{2}{*}{ Figure } & \multirow[b]{2}{*}{ Molecule } & \multicolumn{5}{|c|}{ B3LYP } & \multicolumn{4}{|c|}{$\omega \mathrm{B} 97$} & \multirow[b]{2}{*}{ E5 } \\
\hline & & E1 & E2 & E3 & E4 & E5 & E1 & E2 & E3 & E4 & \\
\hline Fig. 1.A & $\mathrm{C}_{2} \mathrm{H}_{4}+\mathrm{HCNH}^{+} \rightarrow\left[\mathrm{C}_{2} \mathrm{H}_{4}: \mathrm{HCNH}\right]^{+}$ & 3.81 & 3.86 & 5.64 & 5.73 & 7.14 & 5.56 & 5.73 & 7.37 & 7.98 & 8.17 \\
\hline${ }^{1} A^{\prime}$ & Oscillator strength & 0.002 & 0.00 & 0.00 & 0.00 & 0.086 & 0.014 & 0.00 & 0.00 & 0.093 & 0.199 \\
\hline Fig. 1.B & $\mathrm{C}_{2} \mathrm{H}_{4}+\mathrm{HNCH}^{+} \rightarrow\left[\mathrm{C}_{2} \mathrm{H}_{4}: \mathrm{HNCH}\right]^{+}$ & 4.84 & 4.91 & 6.41 & 6.59 & 7.92 & 6.57 & 6.84 & 7.62 & 8.14 & 8.27 \\
\hline${ }^{1} A^{\prime}$ & Oscillator strength & 0.004 & 0.00 & 0.00 & 0.00 & 0.00 & 0.037 & 0.00 & 0.00 & 0.00 & 0.235 \\
\hline Fig. 1.C & $\mathrm{C}_{2} \mathrm{H}_{4}+\mathrm{HCNH}^{+} \rightarrow\left[\mathrm{C}_{2} \mathrm{H}_{4}: \mathrm{HCNH}\right]^{+}$, Boat & 6.71 & 7.41 & 7.61 & 7.93 & 9.55 & 7.01 & 7.74 & 7.99 & 8.56 & 9.79 \\
\hline${ }^{1} A^{\prime}$ & Oscillator strength & 0.00 & 0.003 & 0.105 & 0.095 & 0.001 & 0.00 & 0.002 & 0.15 & 0.076 & 0.001 \\
\hline Fig. 1.D & $\mathrm{C}_{2} \mathrm{H}_{4}+\mathrm{HCNH}^{+} \rightarrow\left[\mathrm{C}_{2} \mathrm{H}_{4}: \mathrm{HCNH}\right]^{+}$, Bridge & 3.51 & 6.54 & 6.7 & 7.27 & 7.97 & 3.68 & 6.98 & 7.13 & 7.65 & 8.54 \\
\hline${ }^{1} A^{\prime}$ & Oscillator strength & 0.001 & 0.003 & 0.029 & 0.012 & 0.248 & 0.001 & 0.041 & 0.029 & 0.025 & 0.343 \\
\hline Fig. 2.A & $\mathrm{C}_{2} \mathrm{H}_{4}+\mathrm{H}_{2} \mathrm{CNH}_{2}^{+} \rightarrow\left[\mathrm{C}_{2} \mathrm{H}_{4}: \mathrm{H}_{2} \mathrm{CNH}_{2}\right]^{+}$ & 4.62 & 5.86 & 6.97 & 7.37 & 7.62 & 5.32 & 7.28 & 7.61 & 8.04 & 8.44 \\
\hline${ }^{1} A^{\prime}$ & Oscillator strength & 0.309 & 0.00 & 0.023 & 0.139 & 0.003 & 0.314 & 0.00 & 0.245 & 0.00 & 0.001 \\
\hline Fig. $2 . B$ & $\mathrm{C}_{2} \mathrm{H}_{4}+\mathrm{H}_{2} \mathrm{CNH}_{2}^{+} \rightarrow\left[\mathrm{C}_{2} \mathrm{H}_{4}: \mathrm{H}_{2} \mathrm{CNH}_{2}\right]^{+}$, Boat & 8.81 & 8.87 & 9.66 & 9.92 & 10.03 & 9.71 & 9.97 & 10.68 & 10.87 & 10.88 \\
\hline${ }^{1} A$ & Oscillator strength & 0.019 & 0.004 & 0.032 & 0.004 & 0.044 & 0.026 & 0.003 & 0.031 & 0.006 & 0.005 \\
\hline Fig. 3.A & $\mathrm{HCCH}+\mathrm{HCNH}^{+} \rightarrow[\mathrm{HCCH}: \mathrm{HCNH}]^{+}$ & 4.12 & 4.31 & 4.4 & 4.5 & 6.73 & 5.8 & 6.08 & 6.39 & 6.45 & 7.12 \\
\hline${ }^{1} A_{1}$ & Oscillator strength & 0.00 & 0.016 & 0.001 & 0.00 & 0.00 & 0.00 & 0.002 & 0.00 & 0.014 & 0.00 \\
\hline Fig. 3.B & $\mathrm{HCCH}+\mathrm{HNCH}^{+} \rightarrow[\mathrm{HCCH}: \mathrm{HNCH}]^{+}$ & 4.89 & 5.1 & 5.34 & 5.45 & 6.74 & 6.19 & 6.81 & 7.39 & 7.44 & 7.51 \\
\hline${ }^{1} A_{1}$ & Oscillator strength & 0.00 & 0.014 & 0.001 & 0.00 & 0.00 & 0.00 & 0.001 & 0.012 & 0.00 & 0.00 \\
\hline Fig. 3.C & $\mathrm{HCCH}+\mathrm{HNCH}^{+} \rightarrow[\mathrm{HCCH}: \mathrm{HNCH}]^{+}$, Boat & 2.81 & 5.62 & 6.52 & 7.37 & 7.4 & 3.03 & 5.82 & 6.85 & 7.72 & 7.92 \\
\hline${ }^{1} A^{\prime}$ & Oscillator strength & 0.005 & 0.00 & 0.00 & 0.00 & 0.027 & 0.005 & 0.00 & 0.00 & 0.00 & 0.035 \\
\hline Fig. 4 & $\mathrm{HCN}+\mathrm{C}_{2} \mathrm{H}_{3}^{+} \rightarrow\left[\mathrm{HCN}: \mathrm{C}_{2} \mathrm{H}_{3}\right]^{+}$ & 5.1 & 5.76 & 7.25 & 7.65 & 8.35 & 5.73 & 6.08 & 7.52 & 8.19 & 8.68 \\
\hline${ }^{1} A^{\prime}$ & Oscillator strength & 0.00 & 0.3 & 0.00 & 0.00 & 0.11 & 0.00 & 0.327 & 0.00 & 0.00 & 0.264 \\
\hline Fig. 5.A & $\mathrm{HCC}^{+}+\mathrm{HCN} \rightarrow \mathrm{HCCHCN}^{+}$, Branched & 3.06 & 3.33 & 4.9 & 5.34 & 6.39 & 3.17 & 3.39 & 5.6 & 6.04 & 7.69 \\
\hline${ }^{1} A^{\prime}$ & Oscillator strength & 0.00 & 0.007 & 0.011 & 0.021 & 0.365 & 0.00 & 0.009 & 0.016 & 0.177 & 0.299 \\
\hline Fig. 5.B & $\mathrm{HCC}^{+}+\mathrm{NCH} \rightarrow[\mathrm{HCCNCH}]^{+}$, Linear & 4.32 & 4.46 & 4.47 & 7.46 & 8.74 & 4.46 & 4.66 & 4.67 & 7.89 & 8.67 \\
\hline${ }^{1} \Sigma$ & Oscillator strength & 0.00 & 0.00 & 0.00 & 1.058 & 0.00 & 0.00 & 0.00 & 0.00 & 1.249 & 0.00 \\
\hline Fig. 6.A & $\mathrm{HCCC}^{+}+\mathrm{HCN} \rightarrow[\mathrm{HCCC}(\mathrm{H}) \mathrm{NCH}]^{+}$, Branched & 1.62 & 1.7 & 4.32 & 4.39 & 5.11 & 1.66 & 2.26 & 5.08 & 6.41 & 6.44 \\
\hline${ }^{1} A^{\prime}$ & Oscillator strength & 0.00 & 0.003 & 0.006 & 0.001 & 0.00 & 0.00 & 0.006 & 0.187 & 0.104 & 0.00 \\
\hline Fig. $6 . B$ & $\mathrm{HCCC}^{+}+\mathrm{HCN} \rightarrow[\mathrm{HCCCNCH}]^{+}$, Linear & 0.83 & 3.21 & 4.32 & 4.62 & 5.37 & 0.89 & 3.44 & 4.54 & 5.47 & 5.74 \\
\hline${ }^{1} A^{\prime}$ & Oscillator strength & 0.001 & 0.001 & 0.028 & 0.002 & 0.315 & 0.001 & 0.001 & 0.062 & 0.003 & 0.343 \\
\hline Fig. 7 & $\mathrm{H}_{2} \mathrm{CCH}_{2}+\mathrm{H}_{2} \mathrm{CNH}^{+} \rightarrow\left[\mathrm{H}_{2} \mathrm{CCH}_{2}: \mathrm{H}_{2} \mathrm{CNH}\right]^{+}$ & 2.27 & 3.39 & 3.81 & 4.15 & 4.4 & 2.29 & 3.67 & 4.09 & 4.61 & 4.77 \\
\hline${ }^{2} A^{\prime}$ & Oscillator strength & 0.23 & 0.00 & 0.001 & 0.003 & 1.00 & 0.21 & 0.002 & 0.003 & 0.001 & 0.01 \\
\hline Fig. 8.A & $\mathrm{H}_{2} \mathrm{CNH}_{2}+\mathrm{H}_{2} \mathrm{CNH}_{2}^{+} \rightarrow\left[\mathrm{H}_{2} \mathrm{CNH}_{2}\right]_{2}^{+}$, Pi-stack & 2.86 & 4.29 & 4.94 & 5.16 & 5.23 & 2.5 & 4.89 & 5.43 & 5.48 & 5.78 \\
\hline${ }^{2} A^{\prime}$ & Oscillator strength & 0.208 & 0.018 & 0.00 & 0.00 & 0.00 & 0.237 & 0.008 & 0.015 & 0.00 & 0.00 \\
\hline Fig. 8.B & $\mathrm{H}_{2} \mathrm{CNH}_{2}+\mathrm{H}_{2} \mathrm{CNH}_{2}^{+} \rightarrow\left[\mathrm{H}_{2} \mathrm{CNH}_{2}\right]_{2}^{+}$, Trans & 3.01 & 4.99 & 5.68 & 6.16 & 6.38 & 3.02 & 4.99 & 5.68 & 6.16 & 6.38 \\
\hline${ }^{2} A^{\prime}$ & Oscillator strength & 0.195 & 0.00 & 0.00 & 0.002 & 0.00 & 0.195 & 0.00 & 0.00 & 0.002 & 0.00 \\
\hline
\end{tabular}

Notes. Underneath the excitation energies the dimensionless oscillator strengths are presented. The electronic ground state is noted in the column with the figure name (the row below the figure name). $1 \mathrm{eV}=23.0605 \mathrm{kcal} \mathrm{mol}^{-1}=1.16045 \times 10^{4} \mathrm{~K}$.

(1.96 kcal/mol). However, as Fig. 1.D shows, after association, the geometry changes significantly from the initial monomer geometries, which also explains why the association energy for an ion/neutral complex is small in this case in the association some new bonds are formed, but also some other bonds are weakened. A BSSE correction in the situation where the two monomer units do not retain their monomer quality but rather react to become one molecule is uninformative. Thus, BSSE corrections have not been computed for the ion/neutral complexes included in the present study.

II. $\left[\mathrm{H}_{2} \mathrm{CCH}_{2}-\mathrm{H}_{2} \mathrm{CNH}_{2}\right]^{+}$. Methyleneimine, $\mathrm{H}_{2} \mathrm{CNH}$, is observed in various interstellar environments (Johnson \& Lovas 1972). Planar protonated methyleneimine can bind with ethylene by a face-to-face stacking interaction. The parallel-displaced face stacked dimer cation of these two species is presented as isomer $\mathrm{A}$ in Fig. 2. The $\mathrm{H}_{2} \mathrm{CNH}_{2}^{+}$moiety is slipped from the center upon optimization (this complex has Cs symmetry), with the nitrogen pointing outwards at a right angle. At the MP2/aug-ccpVTZ optimized geometry, the nearest carbon-carbon distance between the two moieties is 2.781 , and the binding energy is $9.36 \mathrm{kcal} \mathrm{mol}^{-1}$ relative to the ethylene and methylene amine cation dissociation channel. Upon further single-point refinement at the $\operatorname{CCSD}(\mathrm{T}) /$ aug-cc-pVTZ level of theory, the binding energy is $7.70 \mathrm{kcal} \mathrm{mol}^{-1}$. This relatively weak dimer complex is bound by the attraction of the diffuse $\pi$ electron cloud and the positive charge of the closed shell methylene amine cation. This example shows how simple double-bonded species, including nitrogen containing ones, can form stacked complexes with small but non-negligible binding energies by electrostatic interactions when one monomer is charged. The $\left[\mathrm{H}_{2} \mathrm{CCH}_{2}-\right.$ $\left.\mathrm{H}_{2} \mathrm{CNH}_{2}\right]^{+}$complex, Fig. 2.A, has several singlet-singlet electronic excitation bands in the UV; one around $4.62 \mathrm{eV}(266 \mathrm{~nm})$ has the strongest oscillator strength of 0.31 . At the $\omega \mathrm{B} 97 / \mathrm{cc}-$ pVTZ level of theory the excitation energy for the same strong excitation band is $5.32 \mathrm{eV}$, which is much closer to the excitation energy, $5.62 \mathrm{eV}$, obtained at the EOM-CCSD/cc-pVTZ level of theory. The excitation energies calculated using B3LYP and $\omega \mathrm{B} 97$ for all complexes studied are presented in Table 3. A more strongly bound four-membered cyclic structure, presented as B in Fig. 2, is also located, with $31.10 \mathrm{kcal} \mathrm{mol}^{-1}$ binding energy. This cyclic, slightly puckered structure is interesting as it incorporates a $\mathrm{N}$ atom in the ring, indicating the ease of ring formation in the gas phase due to electrostatic attraction. Which of these two product channels is obtained will 
Table 4. Excitation energies (in eV) and oscillator strengths of selected molecules and ions using time-dependent density functional theory (TDDFT) with B3LYP/cc-pVTZ and $\omega$ B97/cc-pVTZ.

\begin{tabular}{|c|c|c|c|c|c|c|c|c|c|c|}
\hline \multirow[b]{2}{*}{ Molecule } & \multicolumn{5}{|c|}{ B3LYP } & \multicolumn{4}{|c|}{$\omega \mathrm{B} 97$} & \multirow[b]{2}{*}{ E5 } \\
\hline & E1 & $\overline{\mathrm{E} 2}$ & E3 & E4 & E5 & E1 & E2 & E3 & $\overline{\mathrm{E} 4}$ & \\
\hline HCCH, Excitation energy & 8.39 & 8.67 & 8.67 & 12.42 & 12.42 & 8.34 & 8.72 & 8.72 & 13.17 & 13.17 \\
\hline${ }^{1} \Sigma_{q}^{+}$, Oscillator strength & 0.00 & 0.00 & 0.00 & 0.007 & 0.007 & 0.00 & 0.00 & 0.00 & 0.009 & 0.009 \\
\hline $\mathrm{H}_{2} \mathrm{CCH}_{2}$, Excitation energy & 7.89 & 7.91 & 8.18 & 8.6 & 8.83 & 7.89 & 8.33 & 8.6 & 9.38 & 9.64 \\
\hline${ }^{1} A_{g}$, Oscillator strength & 0.363 & 0.028 & 0.00 & 0.00 & 0.00 & 0.385 & 0.00 & 0.034 & 0.00 & 0.00 \\
\hline HCN, Excitation energy & 7.71 & 8.00 & 8.00 & 9.17 & 9.17 & 7.63 & 8.02 & 8.02 & 9.41 & 9.41 \\
\hline${ }^{1} \Sigma^{+}$, Oscillator strength & 0.00 & 0.00 & 0.00 & 0.019 & 0.019 & 0.00 & 0.00 & 0.00 & 0.019 & 0.019 \\
\hline $\mathrm{HCNH}^{+}$, Excitation energy & 8.39 & 8.67 & 8.67 & 12.42 & 12.43 & 8.36 & 8.71 & 8.71 & 13.17 & 13.17 \\
\hline${ }^{1} \Sigma$, Oscillator strength & 0.00 & 0.00 & 0.00 & 0.007 & 0.007 & 0.00 & 0.00 & 0.00 & 0.009 & 0.009 \\
\hline $\mathrm{H}_{2} \mathrm{CNH}_{2}^{+}$, Excitation energy & 7.94 & 9.52 & 10.8 & 11.33 & 12.2 & 8.04 & 9.53 & 10.91 & 11.97 & 12.79 \\
\hline${ }^{1} A_{1}$, Oscillator strength & 0.00 & 0.297 & 0.008 & 0.032 & 0.00 & 0.00 & 0.302 & 0.009 & 0.039 & 0.00 \\
\hline $\mathrm{H}_{2} \mathrm{CNH}^{+}$, Excitation energy & 3.58 & 5.59 & 5.85 & 6.89 & 8.34 & 3.49 & 5.65 & 5.91 & 7.17 & 8.58 \\
\hline${ }^{1} A^{\prime}$, Oscillator strength & 0.00 & 0.00 & 0.001 & 0.014 & 0.006 & 0.00 & 0.00 & 0.002 & 0.013 & 0.004 \\
\hline $\mathrm{H}_{2} \mathrm{CNH}_{2}$, Excitation energy & 3.05 & 4.22 & 4.33 & 6.13 & 6.65 & 3.89 & 5.11 & 5.11 & 6.72 & 7.13 \\
\hline${ }^{2} A^{\prime}$, Oscillator strength & 0.00 & 0.00 & 0.007 & 0.00 & 0.127 & 0.00 & 0.008 & 0.00 & 0.131 & 0.00 \\
\hline
\end{tabular}

Notes. The electronic ground state is noted in the column with the molecule name.

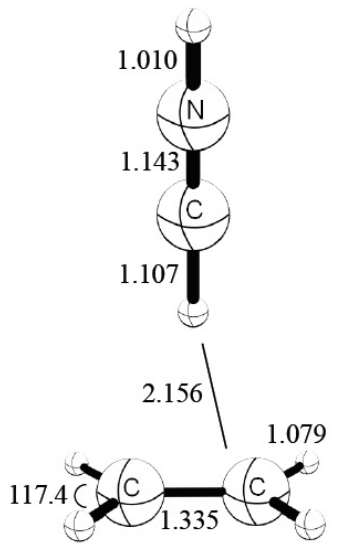

A, BE 11.70

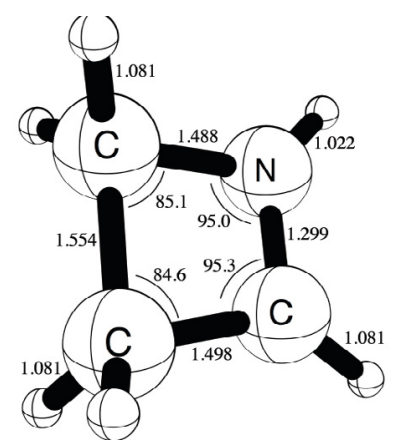

C, BE 50.07

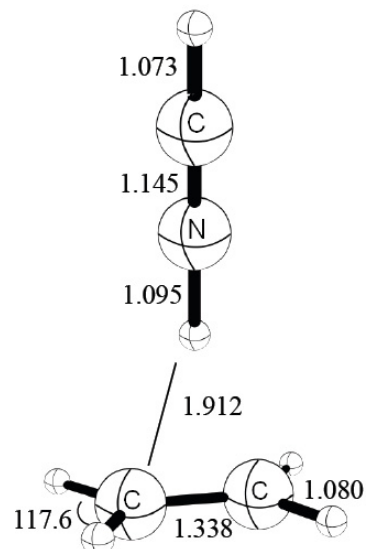

B, $\quad$ BE16.58

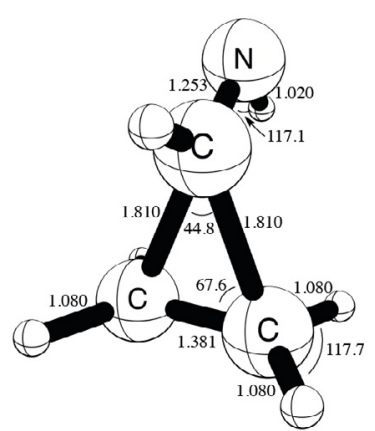

D, BE 1.96

Fig. 1. MP2/aug-cc-pVTZ optimized geometry of the encounter complexes between $\mathrm{HNCH}^{+}$and $\mathrm{H}_{2} \mathrm{CCH}_{2}$. Bond lengths are expressed in $\AA$ and angles in degrees. Binding energies (BE, in $\mathrm{kcal} \mathrm{mol}^{-1}$ ) are presented next to the figure labels.

depend to some extent on the relative orientation of the reactant partners as they reach association distance, though there will be a large thermodynamic driving force towards isomer B. Further association of ring structure $\mathrm{B}$ with acetylene might produce a six-membered carbon/nitrogen cyclic molecule.

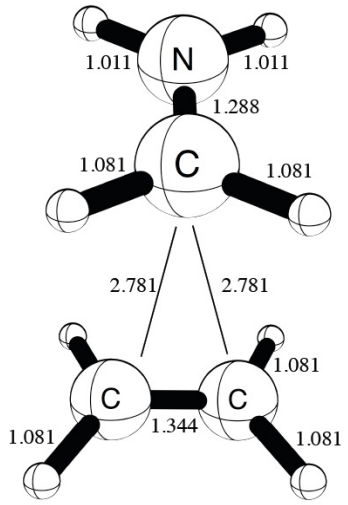

A, BE 7.70

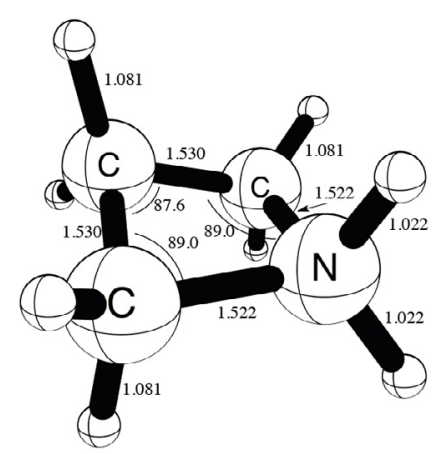

B, $\quad$ BE 32.01
Fig. 2. Electrostatically bound closed shell $\pi$-complex and boat structure between the $\mathrm{H}_{2} \mathrm{CCH}_{2}$ and $\mathrm{H}_{2} \mathrm{CNH}_{2}^{+}$ion, presented here at the MP2/aug-cc-PVTZ level of theory. Bond angles are expressed in $\AA$ and angles in degrees. Binding energies (BE, in $\mathrm{kcal} \mathrm{mol}^{-1}$ ) are presented next to the figure labels.

III. $[\mathrm{HCCH}-\mathrm{HCNH}]^{+}$and $[\mathrm{HCCH}-\mathrm{HNCH}]^{+}$. Acetylene and $\mathrm{HCNH}^{+}$are both observed in the ISM (Ziurys \& Turner 1986). In total, three isomers that can be formed by barrierless association between $\mathrm{HCCH}$ and $\mathrm{HCNH}^{+}$have been located on the singlet potential energy surface of the complex. Two T-shaped weakly bound complexes as well as a slightly more strongly bound cyclic isomer are presented in Fig. 3. In both T-shaped structures, shown as A and B in Fig. 3, the terminal $\mathrm{H}$ atoms of $\mathrm{HCNH}^{+}$are attracted by the $\pi$ electron cloud of $\mathrm{HCCH}$. In $\mathrm{HCNH}^{+}$, the positive charge is distributed over all four atoms, but the $\mathrm{N}$-terminal $\mathrm{H}$ atom has the most positive charge, hence the electrostatic attraction between that $\mathrm{H}$ atom and the $\pi$ electron cloud of $\mathrm{HCCH}$ is stronger relative to the $\mathrm{C}$-terminal $\mathrm{H}$ atom, and therefore the $\mathrm{N}$-terminal $\mathrm{H}$ atom makes a stronger bond with the acetylene than the $\mathrm{C}$ terminal $\mathrm{H}$-atom. The binding energies are presented in Table 1. The [HCCH$\mathrm{HCNH}]^{+}$complex is bound by $12.56 \mathrm{kcal} \mathrm{mol}^{-1}$ at the MP2/augcc-pVTZ level and $11.53 \mathrm{kcal} \mathrm{mol}^{-1}$ at the $\operatorname{CCSD}(\mathrm{T}) /$ aug-ccpVTZ level with respect to the $\mathrm{HCCH}$ and $\mathrm{HCNH}^{+}$dissociation 


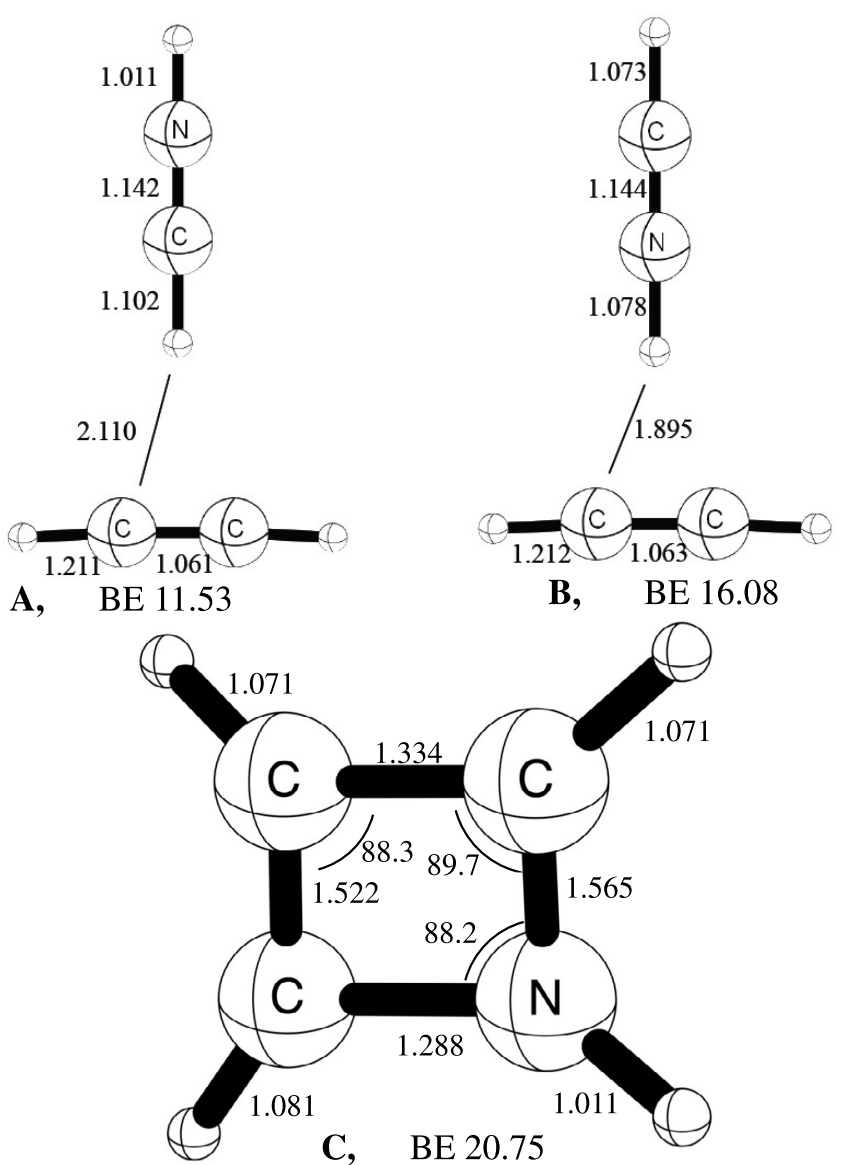

Fig. 3. Electrostatically bound closed shell $\pi$-complex and boat structure between the $\mathrm{H}_{2} \mathrm{CCH}_{2}$ and $\mathrm{H}_{2} \mathrm{CNH}_{2}^{+}$ion, presented here at the MP2/aug-cc-PVTZ level of theory. Bond angles are expressed in $\AA$ and angles in degrees. Binding energies (BE, in $\mathrm{kcal} \mathrm{mol}^{-1}$ ) are presented next to the figure labels.

channel. Dissociating the more strongly bound $[\mathrm{HCCH}-$ $\mathrm{HNCH}]^{+}$T-shaped complex into $\mathrm{HCCH}$ and $\mathrm{HCNH}^{+}$will require 18.49 and $16.08 \mathrm{kcal} \mathrm{mol}^{-1}$ at the MP2/aug-cc-pVTZ and $\operatorname{CCSD}(\mathrm{T}) / \mathrm{aug}$-cc-pVTZ levels, respectively. As seen in Fig. 3, [HCCH-HNCH $]^{+}$has a shorter NH distance (1.895) relative to the $\mathrm{CH}$ distance, in $[\mathrm{HCCH}-\mathrm{HCNH}]^{+}, 2.110$. Perhaps surprisingly, unlike the T-shaped complexes of $\mathrm{HCNH}^{+}$and $\mathrm{H}_{2} \mathrm{CCH}_{2}$ discussed earlier (in Fig. 1), these complexes have weak electronic transitions in the ultraviolet. There is a cyclic isomer, presented in Fig. 3, with a four-membered ring and a slightly larger binding energy, relative to $[\mathrm{HCCH}-\mathrm{HNCH}]^{+}$, of $20.75 \mathrm{kcal} \mathrm{mol}^{-1}$ at the CCSD(T)/aug-cc-pVTZ level. This is the simplest cyclic structure that incorporates a $\mathrm{N}$ atom into its framework. Calculated electronic excitation energies for all structures are presented in the Table 3 . The difference in excitation energies between B3LYP $(4.12 \mathrm{eV})$ and $\omega$ B97 $(5.80 \mathrm{eV})$ DFT methods stems from the fact that B3LYP is not suitable for predicting excitations that have an associated charge transfer component. Of the two density functionals employed here, the $\omega \mathrm{B} 97$ excitation energy comes much closer to that obtained by the EOM-CCSD/cc-pVTZ method (7.0 eV).

IV. $\left[\mathrm{HCN}-\mathrm{H}_{2} \mathrm{CCH}\right]^{+}$. Another potentially viable mechanism for carbonaceous chain growth involves association of very abundant nitriles, such as $\mathrm{HCN}$, and unsaturated molecular cations or fragment cations like vinyl cation. Steered by electrostatic

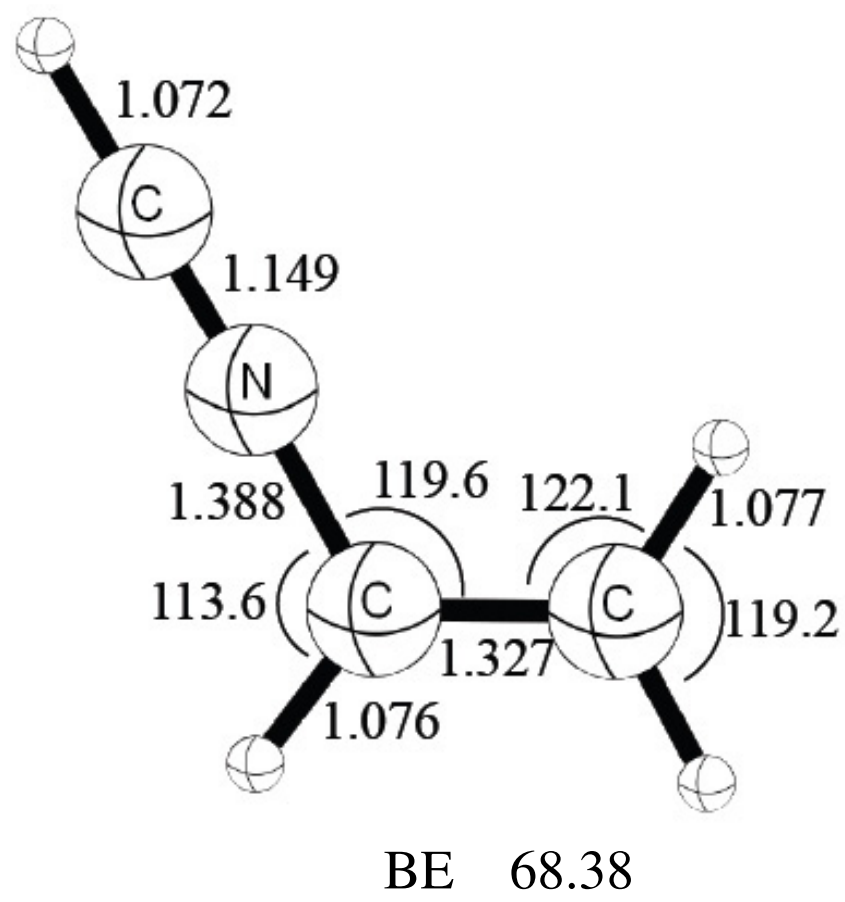

Fig. 4. Electrostatically bound closed shell $\pi$-complex and boat structure between the $\mathrm{H}_{2} \mathrm{CCH}^{+}$and $\mathrm{HCN}$, presented here at the MP2/augcc-PVTZ level of theory. Bond angles are expressed in $\AA$ and angles in degrees. Binding energies (BE, in $\mathrm{kcal} \mathrm{mol}^{-1}$ ) are presented under the figure.

ion-dipole attraction, vinyl cation can be associated with polar hydrogen cyanide, incorporating nitrogen in the chain growth process. Association of $\mathrm{HCN}$ with vinyl cation results in the formation of a strong covalently bound closed shell molecular cation. The MP2/aug-cc-pVTZ optimized geometry of this species, vinyl isocyanide cation, is shown in Fig. 4. Loss of a hydrogen from this complex leads to $\mathrm{C}_{3} \mathrm{H}_{3} \mathrm{~N}^{+}$which was found to form in the selected ion flow tube during UV induced dissociation of pyrimidine and may be a key species in pyrimidine formation (Bera et al. 2009; Fondren et al. 2007).

In vinyl isocyanide cation (see Fig. 4), the lone-pair electron on nitrogen donates into the vacant carbon $\pi$ orbital to form a strong $\mathrm{CN}$ sigma bond. The central $\mathrm{sp}^{2}$ hybridized carbon makes a short single bond, 1.388, with the sp hybridized nitrogen. At the MP2/aug-cc-pVTZ level of theory the binding energy is $71.57 \mathrm{kcal} \mathrm{mol}^{-1}$ relative to the $\mathrm{H}_{2} \mathrm{CCH}^{+}$and $\mathrm{HCN}$ dissociation channel. At the CCSD(T)/aug-cc-pVTZ level, the binding energy is $68.38 \mathrm{kcal} \mathrm{mol}^{-1}$ using the geometries optimized at the MP2/aug-cc-pVTZ level. The singlet ground state to singlet excited state vertical excitation energies obtained with TDDFT at the B3LYP/cc-pVTZ level of theory shows that the molecule has two relatively strong peaks in the UV at $8.35 \mathrm{eV}$ $(149 \mathrm{~nm})$ and $5.76 \mathrm{eV}(215 \mathrm{~nm})$, with oscillator strengths of 0.11 and 0.30 , respectively. The excitation energies (in eV) and oscillator strengths calculated at the B3LYP/cc-pVTZ and $\omega$ B97/ccpVTZ levels of theories are included in Table 3, and are in quite good agreement with each other.

V. $[\mathrm{HCN}-\mathrm{HCC}]^{+}$. The neutral molecule acetylene $(\mathrm{HCCH})$ and the acetyl radical (HCC) are observed species in the ISM, as is neutral $\mathrm{C} 2$. Protonated carbon $\mathrm{CH}^{+}$has also been observed, however, $\mathrm{HCC}^{+}$is as yet unobserved. Protonation of $\mathrm{C} 2$ will most likely produce $\mathrm{HCC}^{+}$in the ISM, though the abundance 


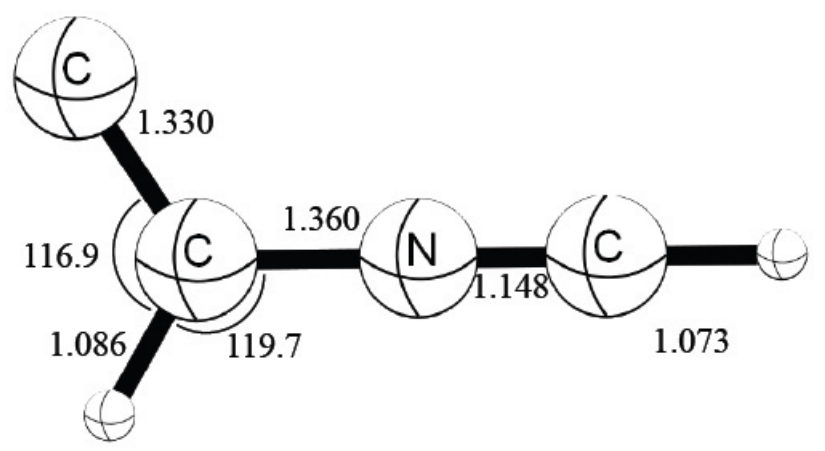

A, BE 154.3

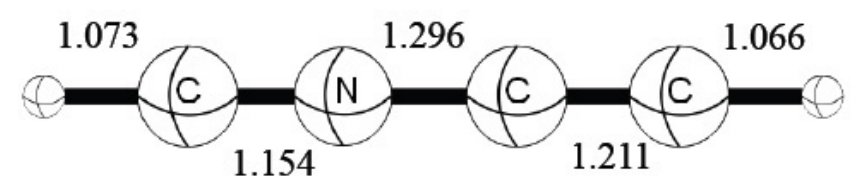

B, BE 205.6

Fig. 5. Closed shell complexes of $\mathrm{HCC}^{+}$and $\mathrm{HCN}$ or vice versa, presented here at the MP2/aug-cc-PVTZ level of theory. Bond angles are expressed in $\AA$ and angles in degrees. Binding energies (BE, in $\mathrm{kcal} \mathrm{mol}^{-1}$ ) are presented under the figure.

of $\mathrm{HCC}^{+}$in the ISM may be low due to its fast exothermic reaction with $\mathrm{H}_{2}$ (McWan et al. 1999). Reaction between two closed shell species, acetyl cation $\left(\mathrm{HCC}^{+}\right)$and hydrogen cyanide leads to two structural isomers: branched $\mathrm{HCNC}(\mathrm{H}) \mathrm{C}^{+}$and linear $\mathrm{HCCNCH}^{+}$, whose MP2/aug-cc-pVTZ structures are presented in Fig. 5. A $\pi$ complex between closed shell $\mathrm{HCC}^{+}$ and $\mathrm{HCN}$ is not stable due to very strong electrostatic attraction. The $\mathrm{N}$ lone pair of electrons in $\mathrm{HCN}$ can donate into the empty $\pi$ orbital of the acetyl cation to make a strong sigma bond. The binding energies for these two isomers are very strong, 134.42 and $198.26 \mathrm{kcal} \mathrm{mol}^{-1}$, respectively at the same level of theory. Binding energies refined at the $\operatorname{CCSD}(\mathrm{T}) /$ augcc-pVTZ level for the $\mathrm{HCC}^{+}$and $\mathrm{HCN}$ dissociation channel are 154.30 and $205.59 \mathrm{kcal} \mathrm{mol}^{-1}$ for branched (Fig. 5) and linear isomers, respectively. The branched isomer has ten electronic absorption lines in the ultraviolet ranging from approximately $8.59 \mathrm{eV}$ to $3.06 \mathrm{eV}$ (144 nm to $405 \mathrm{~nm}$ ). One of these bands at $6.39 \mathrm{eV}(195 \mathrm{~nm})$ exhibits a relatively strong oscillator strength of 0.36 , while all others are weak. The linear isomer has only one very strong electronic excitation line at $166 \mathrm{~nm}$ with oscillator strength 1.1 computed at the TDDFT B3LYP/cc-pVTZ level of theory. Other excitations have nearly zero oscillator strength. For this case, the excitation energies and oscillator strengths computed with the B3LYP and range separated $\omega$ B97 functionals are in good agreement with each other (Table 3).

VI. $[\mathrm{HCCC}-\mathrm{HCN}]^{+}$. The encounter between the $\mathrm{HCCC}^{+}$ion and $\mathrm{HCN}$ leads to two structural isomers, presented in Fig. 6. A $\pi$ complex of $\mathrm{HCCC}^{+}$with $\mathrm{HCN}$ does not exist. However, the $\sigma$-bonded complexes are stable. The geometries optimized at the MP2/aug-cc-pVTZ level of theory are presented in Fig. 6. The binding energies, presented in Table 1, for the branched and the linear isomers are 40.42 and $55.03 \mathrm{kcal} \mathrm{mol}^{-1}$ respectively at the above mentioned level of theory. Binding energies relative to the $\mathrm{HCCC}^{+}$and $\mathrm{HCN}$ dissociation channel further refined at the $\operatorname{CCSD}(\mathrm{T}) /$ aug-cc-pVTZ level are 38.70 and $48.81 \mathrm{kcal} \mathrm{mol}^{-1}$

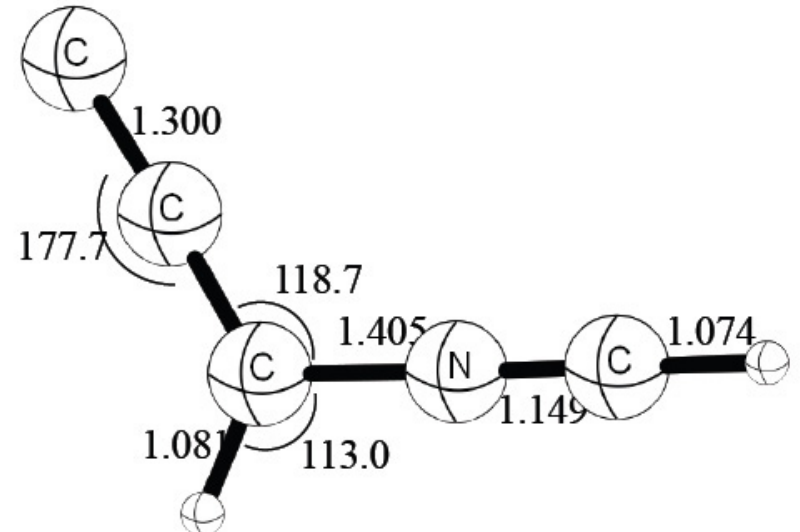

A, $\quad$ BE 38.7

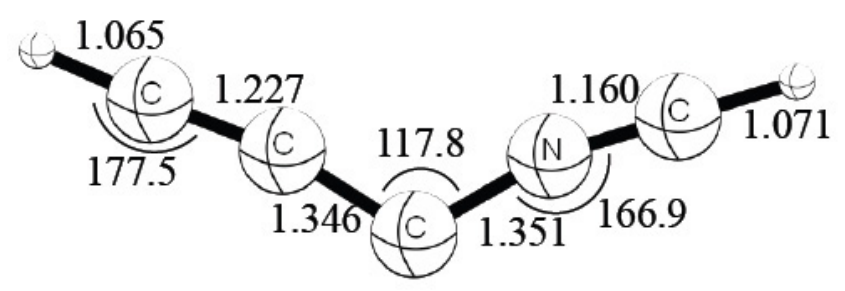

B, $\quad$ BE 48.81

Fig. 6. Closed shell complexes of $\mathrm{HCCC}^{+}$and $\mathrm{HCN}$ or vice versa, presented here at the MP2/aug-cc-PVTZ level of theory. Bond angles are expressed in $\AA$ and angles in degrees. Binding energies (BE, in $\mathrm{kcal} \mathrm{mol}^{-1}$ ) are presented under the figure next to the labels.

for the branched and the linear isomers (see Fig. 6). Both isomers have very strong electronic absorption signatures in the UV. One electronic excitation at $0.83 \mathrm{eV}$ (B3LYP) or $0.89 \mathrm{eV}$ $(\omega \mathrm{B} 97)$, as presented in Table 3, falls into the infrared region. Oscillator strengths and excitation energies for these complexes computed using TDDFT B3LYP/cc-pVTZ and $\omega$ B97/cc-pVTZ are presented in Table 3.

\subsection{Open shell cations}

VII. $\left[\mathrm{H}_{2} \mathrm{CCH}_{2}-\mathrm{H}_{2} \mathrm{CNH}\right]^{+}$. The open shell cationic complex of $\mathrm{H}_{2} \mathrm{CNH}^{+}\left(\mathrm{H}_{2} \mathrm{CNH}\right.$ is an observed species in the ISM) (Gerakins 2011) with ethylene is an intriguing system. One proton linked to the carbon atom in $\mathrm{H}_{2} \mathrm{CNH}^{+}$is bound with the $\pi$-electron cloud of $\mathrm{H}_{2} \mathrm{CCH}_{2}$ in this cationic complex. The binding energy between $\mathrm{H}_{2} \mathrm{CCH}_{2}$ and $\mathrm{H}_{2} \mathrm{CNH}^{+}$is $11.25 \mathrm{kcal} \mathrm{mol}^{-1}$ at the UMP2/aug-cc-pVTZ level (Table 2). The optimized geometry is presented in Fig. 7. ZAPT2/cc-pVTZ predicts the binding energy to be $9.44 \mathrm{kcal} / \mathrm{mol}$ and at the CCSD(T)/cc-pVTZ level, the binding energy is $10.28 \mathrm{kcal} \mathrm{mol}^{-1}$. The valence electronic excitation energies and oscillator strengths computed with the B3LYP/cc-pVTZ and $\omega$ B97/cc-pVTZ TDDFT methods are given in Table 3 and presented in Fig. 9 as a spectrum. The spectrum has multiple lines in the UV/VIS, only one of which at $2.27 \mathrm{eV}(546 \mathrm{~nm})$, has a relatively large oscillator strength of 0.23 . Molecular orbital pictures indicate a charge transfer transition occurring from the highest doubly occupied molecular orbital (HDOMO) to the singly occupied molecular orbital (SOMO) (see Fig. 9) resulting in a very large oscillator strength at a very low wavelength for this electronic transition. For comparison, the excitation energies of the monomeric species are 


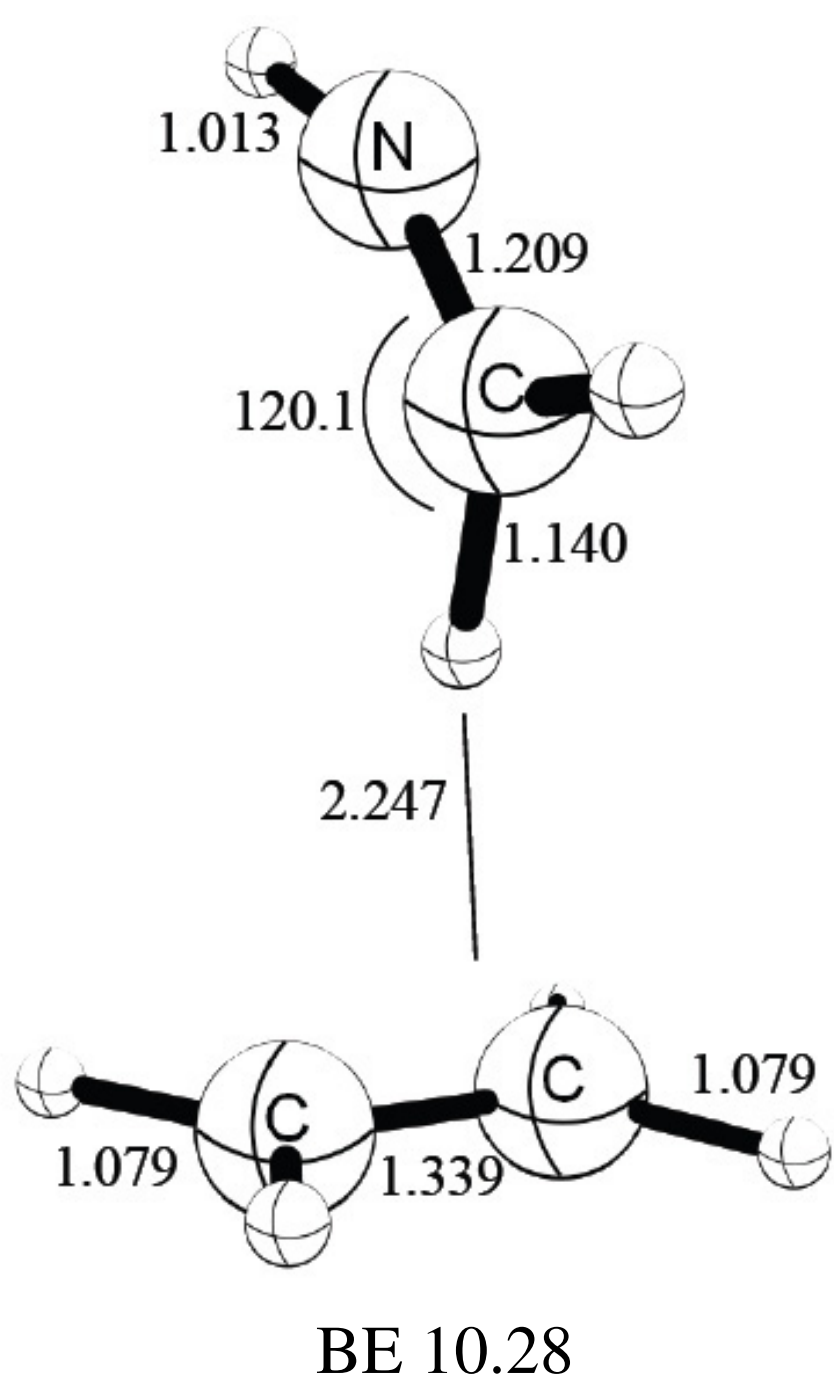

Fig. 7. Structure of weak electrostatically bound association complex of $\mathrm{H}_{2} \mathrm{CNH}^{+}$with $\mathrm{H}_{2} \mathrm{CCH}_{2}$ molecule, presented here at the MP2/augcc-PVTZ level of theory. Bond angles are expressed in $\AA$ and angles in degrees. Binding energies (BE, in $\mathrm{kcal} \mathrm{mol}^{-1}$ ) are presented under the figure.

also presented in Table 4. It is clear that the low energy, intense electronic excitation band is a feature that is exclusive to the complex as there is no such band for either $\mathrm{C}_{2} \mathrm{H}_{4}$ or $\mathrm{H}_{2} \mathrm{CNH}^{+}$.

VIII. $\left[\mathrm{H}_{2} \mathrm{CNH}_{2}-\mathrm{H}_{2} \mathrm{CNH}_{2}\right]^{+}$. Two isomers of the cationic dimer of $\mathrm{H}_{2} \mathrm{CNH}_{2}$ are presented in Fig. 8. One is a linear chain with carbon-carbon connectivity and the other is a $\pi$-stacked complex. The trans isomer, isomer A in Fig. 8, has an elongated $1.774 \mathrm{CC}$ bond, and is bound by $38.42 \mathrm{kcal} \mathrm{mol}^{-1}$ at the UMP2/aug-cc-pVTZ level. Binding energies calculated using ZAPT2 and CCSD(T) with cc-pVTZ basis set are 39.22 and $40.20 \mathrm{kcal} / \mathrm{mol}$ respectively. The MP2/aug-cc-pVTZ optimized structure for isomer B (the $\pi$-stacked complex, see Fig. 8) shows that the carbon nitrogen distance between the monomer units is 2.622 , which is an unusually long bond. The $\pi$-stacked complex is moderately strongly bound with a UMP2/aug-cc-pVTZ binding energy of $22.64 \mathrm{kcal} \mathrm{mol}^{-1}$. The binding energies predicted by the B3LYP (25.49) and ZAPT2 (23.71) levels of theory are also in agreement with that predicted by $\operatorname{CCSD}(\mathrm{T}) / \mathrm{cc}-\mathrm{pVTZ}$ (24.98 kcal/mol). TDDFT calculations, Table 3, reveal electronic

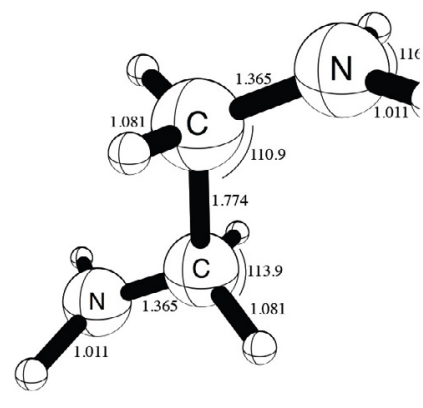

A, $\quad$ BE 40.20

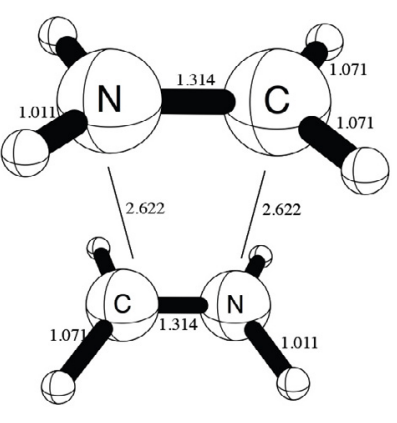

B, $\quad$ BE 24.98
Fig. 8. The structures of the trans association complex and -stacked association complex of $\mathrm{H}_{2} \mathrm{CNH}_{2}$ with $\mathrm{H}_{2} \mathrm{CNH}_{2}^{+}$cation computed at the MP2/aug-cc-PVTZ level of theory. Bond angles are expressed in $\AA$ and angles in degrees. Binding energies (BE, in $\mathrm{kcal} \mathrm{mol}^{-1}$ ) are presented under the figure.

excitation energies with significant oscillator strength for both isomers due to charge-transfer type transitions. The trans isomer has a strong excitation transition at $3.01 \mathrm{eV}(411 \mathrm{~nm})$ with an oscillator strength of 0.19 . The $\pi$-stacked isomer has a strong electronic excitation transition with 0.21 oscillator strength at $2.86 \mathrm{eV}(433 \mathrm{~nm})$.

\subsection{Excitation energies}

Excitation energies were calculated using time dependent density functional theory with two different functionals, the widely used B3LYP and $\omega$ B97 (Chai \& Head-Gordon 2008), for comparison purposes. The electronic excitation calculations reported here refer to bands that would be observed in absorption from the ground electronic state to an excited state. Emission bands, which would likely be similar but shifted, can be calculated, but for this work we have limited the scope to absorption bands. Excitation energies and oscillator strengths of the complexes are presented in Table 3, and that of the constituting molecules and ions are presented in Table 4. For tightly bound covalent complexes, the excitation energies predicted by both the density functionals are in good agreement with each other. However, for the non-covalently bound complexes the electronic excitation energies predicted by B3LYP and $\omega$ B97 functionals can be different by more than $1 \mathrm{eV}$ at times. As mentioned in the methods section, standard density functionals can perform very poorly for charge-transfer type excitations due to self-interaction errors, while range-separated hybrid density functionals, such as $\omega \mathrm{B} 97$, have been shown to perform well in predicting excitation energies of charge transfer states. We have performed more accurate equations of motion coupled cluster singles and doubles (EOM-CCSD) calculations for the cases where the B3LYP and $\omega \mathrm{B} 97$ excitation energies are found to be in disagreement. The EOM-CCSD calculations for the lowest five excited sates for the non-covalently bound complexes show very good agreement with those calculated using the $\omega$ B97 density functional.

We have computed the excitation energies of the five lowest energy excitations of the constituent neutral and ionic species and presented them in Table 4. A comparison of the excitation energies of the constituent monomer neutrals and ions with that of the complexes shows that none of the electronic excitations of the complexes are due to excitation in one constituent only. Some of the excitations are charge transfer in nature between the two moieties in the complex (e.g., Figs. 1.A,B) while others are 
due to complete reorganization of electronic structure after complexation. For example, first excitation energies of $\mathrm{H}_{2} \mathrm{CCH}_{2}$ and $\mathrm{H}_{2} \mathrm{CNH}_{2}^{+}$, given in Table 4, are $7.89 \mathrm{eV}$ and $8.04 \mathrm{eV}$ respectively. The lowest excitation energy of the complex appears at much lower energy, $5.32 \mathrm{eV}$ as given in Table 3, in the near ultra violet due to a charge transfer type transition between $\mathrm{H}_{2} \mathrm{CCH}_{2}$ and $\mathrm{H}_{2} \mathrm{CNH}_{2}^{+}$. The electronic excitation energies produced by using the hybrid functional B3LYP and the range separated $\omega$ B97 agree well for all the species in Table 4 (unlike in the complexes where charge transfer plays a role). These excitation energies of the constituent monomer units can themselves be valuable for observation of these species in the ISM.

\subsection{Astrophysical implications}

The association complexes of mostly observed molecules and ions upon encounter are very interesting from an astrophysical perspective. As found in the present study (Tables 1 and 2), the ion-molecule complexes form with significant association energies that must be dissipated. In the low-density of the ISM, collisions are rare, and therefore, this excess energy is not readily dissipated to third bodies. The excess energy is then either lost radiatively or retained in the internal degrees of freedom of the complexes making the complexes vibrationally and rotationally hot. The weakly bound complexes may therefore have very short lifetimes and dissociate or isomerize to give rise to species other than their parents. However, in the current study we have not investigated dissociation rates for different channels. This could be investigated in the future. The open-shell cations have large oscillator strengths in the visible or near ultraviolet region. Therefore, the open shell nitrogen containing complexes, such as the one presented in Fig. 7 with strong electronic absorption lines in the visible (Fig. 9), are candidates for future laboratory study, and then observational detection. Most of the closed-shell association complexes have large oscillator strengths in the ultraviolet region of the electromagnetic spectrum. Linear conjugated carbonaceous cumulenes are common species in the ISM. Therefore, the linear and branched closed shell association ion-complexes, such as the ones presented in Figs. 4-6, should also be good candidates for future observation. From a growth perspective these nitrogen containing ionic association complexes can also serve as possible points for nucleation into larger molecules, such as nitrogeneous PAHs. The method of incorporation of nitrogen in the carbon framework is also related to how nitrogenous polycyclic molecules could form in the ISM. Identification of some of these intermediate complexes will help in understanding the involvement of nitrogen in the formation process of carbonaceous molecules in ISM.

\section{Conclusions}

Gas phase ion-dipole encounter complexes of observed, and some yet unobserved, interstellar molecules have been studied using density functional theory, Møller-Plesset perturbation theory, and coupled cluster theory methods along with correlation consistent basis sets. Our main conclusion is that the simplest interstellar cations, steered by electrostatics, can initiate grain formation by forming larger chains, small cyclic cations, $\pi$-complexes, and strong ion-dipole complexes. In more detail, cations of some alkenes and alkynes, and nitrogen substituted alkenes and alkynes have been paired with their neutral counterparts making both closed shell and open shell complexes. Several different orientations, e.g. parallel, parallel displaced and T-shaped, of these encounter complexes have been tested for

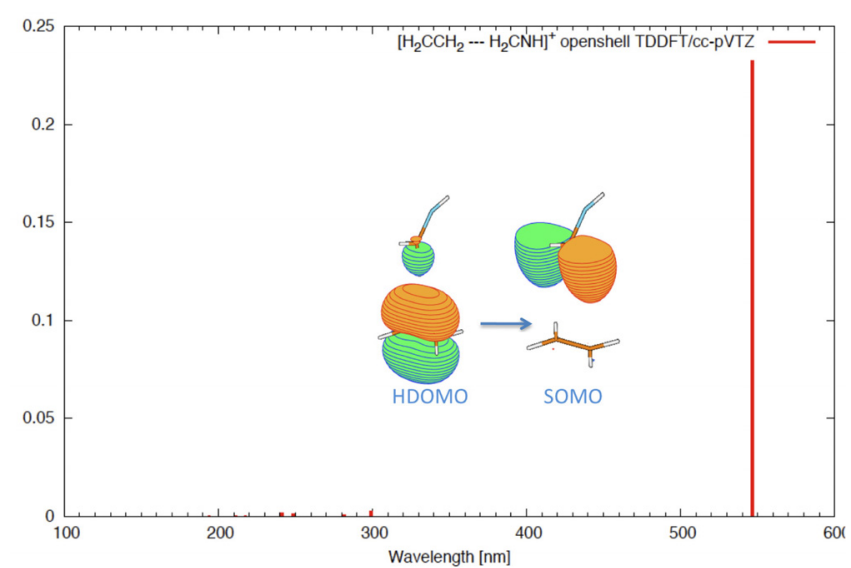

Fig. 9. The absorption spectrum (oscillator strength vs. wavelength $(\mathrm{nm})$ ) of the $\mathrm{H}_{2} \mathrm{CCH}_{2}: \mathrm{H}_{2} \mathrm{CNH}^{+}$complex computed using time dependent density functional theory (TDDFT), at the B3LYP/ccpVTZ level. The inset shows the highest doubly occupied molecular orbital (HDOMO) and the singly occupied molecular orbital (SOMO) of the complex that has a large oscillator strength.

their stability, binding energy and electronic spectra. Acetylene and ethylene, when paired with protonated hydrogen cyanide (i.e. $\mathrm{HCNH}^{+}$), all of which are abundant in the ISM, make strong T-shaped closed-shell encounter complexes in which the proton plays a central role in bonding. Binding energies, ranging from 11.06 to $16.05 \mathrm{kcal} \mathrm{mol}^{-1}$, in these complexes are too strong to be a conventional hydrogen bond and too weak to be a conventional $\sigma$-bond. These examples include the T-shaped complexes in Figs. 1 and 3. Ethylene and $\mathrm{H}_{2} \mathrm{CNH}_{2}^{+}$form a strong parallel-rotated $\pi$ complex. Ethylene and $\mathrm{H}_{2} \mathrm{CNH}_{2}^{+}$also form a more stable four-membered cyclic structure, though its binding energy is significantly less than a typical covalent bond. These examples are shown in Fig. 2. Closed shell $\pi$ complexes of $\mathrm{HCN}$ and species with unfulfilled valencies $\left(\mathrm{HCC}^{+}, \mathrm{HCCC}^{+}\right.$, and vinyl cation) are unstable upon geometry optimization and lead to $\sigma$ bonded complexes with significant binding energies. These examples include Figs. 4-6. Open shell dimer cations of ethylene and $\mathrm{H}_{2} \mathrm{CNH}_{2}^{+}$, and the complex of ethylene with $\mathrm{H}_{2} \mathrm{CNH}^{+}$make stable and strong $\pi$ complexes, Figs. 7 and 8.

To summarize, three types of complexes are predicted to form from the simple association of ions and molecules included in this study. Strong covalently bound molecules, ion-dipole bound complexes, and novel $\pi$-complexes of open shell cations are predicted. Most of the cationic species considered here have large oscillator strength electronic transitions in both the near and vacuum ultraviolet, and sometimes even in the visible region of the electromagnetic spectrum. Many of the electronic transitions with large oscillator strengths are due to charge-transfer type excitations between the monomer units, and are thus likely to be easily observed. The open-shell $\pi$-complexes, interestingly, have very large oscillator strengths in the visible region of the electromagnetic spectrum. This makes them possible candidates for some of the interesting observed interstellar emission features that extend throughout the UV-visible and well into the infrared electromagnetic spectrum.

All of the complexes studied here are formed by ionmolecule reactions without an association barrier. This point is supported by test ion-molecular trajectory calculations acetylene $_{2}^{+}$acetylene and ethylene ${ }_{2}^{+}$, which will be reported in due course (Bera et al., in prep.). Thus, the question of which isomeric structure of a given complex is initially formed depends 
significantly on the encounter geometry of the ion-molecule species, though if there is a large difference in binding energies, there can be thermodynamic driving force towards the more stable complex. This is a question that we have not addressed in this study, but it would be interesting and desirable to perform ab initio trajectory calculations for a range of different impact factors and relative orientations for the complexes studied here to explore the initial isomer distributions. Subsequently, there can be internal rearrangements from one isomeric form to another, which are controlled by the excess internal energy and potential energy surface barriers. Hence, it would be useful to characterize the barriers to internal rearrangements in future work.

Acknowledgements. P.P.B. acknowledges a fellowship award from the National Aeronautics and Space Administration (NASA) postdoctoral program administered by ORAU for NASA. T.J.L. gratefully acknowledge support from the NASA grant 08-APRA08-0050. The authors would like to thank the anonymous referee for constructive suggestions.

\section{References}

Barinovs, G., \& van Hemert, M. C. 2006, ApJ, 636, 923

Bates, D. M., Anderson, J. A., Oloyede, P., \& Tschumper, G. S. 2008, Phys. Chem. Chem. Phys., 10, 2775

Becke, A. D. 1988, Phys. Rev. A, 38, 3098

Becke, A. D. 1993, J. Chem. Phys., 98, 5648

Bera, P. P., Lee, T. J., \& Schaefer, H. F., III. 2009, J. Chem. Phys., 131, 074303

Black, J. H., Dalgarno, A., \& Oppenheimer, M. 1975, ApJ, 199, 633

Cami, J., Bernard-Salas, J., Peeters, E., \& Malek, S. E. 2010, Science, 329, 1180

Chai, J.-D., \& Head-Gordon, M. 2008, J. Chem. Phys., 128, 084106

Chillier, X. D. F., Stone, B. M., Salama, F., \& Allamandola, L. J. 1999, J. Chem.

Phys., 111, 449

Dreuw, A., \& Head-Gordon, M. 2004, J. Am. Chem. Soc., 126, 4007

Dunning, T. H. 1989, J. Chem. Phys., 90, 1007

Fondren, L., McLain, J., Jackson, D., Adams, N., \& Babcock, L. 2007, Int. J. Mass Spectrom., 265, 60

Gerakins, P. 2011, http://science.gsfc.nasa.gov/691/cosmicice/ interstellar.html

Gerlich, D., \& Horning, S. 1992, Chem. Rev., 92, 1509
Halasinski, T. M., Weisman, J. L., Ruiterkamp, R., et al. 2003, J. Phys. Chem. A, 107,3660

Herbst, E. 2001, Chem. Soc. Rev., 30, 168

Herbst, E., Roueff, E., \& Talbi, D. 2010, Mol. Phys., 108, 2171

Hirata, S., Lee, T. J., \& Head-Gordon, M. 1999, J. Chem. Phys., 111, 8904

Hirata, S., Head-Gordon, M., Szczepanski, J., \& Vala, M. 2003, J. Phys. Chem. A, 107,4940

Hopkins, B. W., \& Tschumper, G. S. 2004, J. Phys. Chem. A, 108, 2941

Hudgins, D. M., Bauschlicher, C. W., Jr., \& Allamandola, L. J. 2005, ApJ, 632, 316

Jayatilaka, D., \& Lee, T. J. 1992, Chem. Phys. Lett., 199, 211

Johnson, D. R., \& Lovas, F. J. 1972, Chem. Phys. Lett., 15, 65

Lee, T. J., \& Jayatilaka, D. 1993, Chem. Phys. Lett., 201, 1

Lee, T. J., \& Scuseria, G. E. 1995, in Quantum Mechanical Electronic Structure Calculations with Chemical Accuracy, ed. S. R. Langhoff (Dordrecht, Germany: Kleuwer Academic Publishers), 47

Lee, C., Yang, W., \& Parr, R. G. 1988, Phys. Rev. B, 37, 785

Lee, T. J., Rendell, A. P., Dyall, K. G., \& Jayatilaka, D. 1994, J. Chem. Phys., 100,7400

McWan, M. J., Scott, G. B., Adams, N. G., et al. 1999, ApJ, 513, 287

Purvis, G. D., \& Bartlett, R. J. 1982, J. Chem. Phys., 76, 1910

Raghavachari, K., Trucks, G. W., Pople, J. A., \& Head-Gordon, M. 1989, Chem. Phys. Lett., 157, 479

Rhee, Y. M., Lee, T. J., Gudipati, M. S., Allamandola, L. J., \& Head-Gordon, M. 2007, Proc. Natl. Acad. Sci., 104, 5274

Salama, F., Galazutdinov, G. A., Krełowski, J., Allamandola, L. J., \& Musaev, F. A. 1999, ApJ, 526, 265

Shao, Y., Molnar, L. F., Jung, Y., et al. 2006, Phys. Chem. Chem. Phys., 8, 3172

Sinnokrot, M. O., \& Sherrill, C. D. 2004, J. Phys. Chem. A, 108, 10200

Small, D., Rosokha, S. V., Kochi, J. K., \& Head-Gordon, M. 2005, J. Phys. Chem. A, 109, 11261

Smith, D. 1992, Chem. Rev., 92, 1473

Smith, I. W. M. 2002, Chem. Soc. Rev., 31, 137

Snow, T. P. 2001, Spectrochimica Acta Part A: Molecular and Biomolecular Spectroscopy, 57, 615

Snyder, L. E., \& Buhl, D. 1971, ApJ, 163, L47

Szczepanski, J., \& Vala, M. 1993, Nature, 363, 699

Weisman, J. L., Lee, T. J., \& Head-Gordon, M. 2001, Spectrochim. Acta, 57, 931

Weisman, J. L., Mattioda, A., Lee, T. J., et al. 2005, Phys. Chem. Chem. Phys., 7, 109

Werner, H.-J., \& Knowels, P. J. 2006, MOLPRO, version 2006.1, a package of ab initio programs, H.-J. Werner, P. J. Knowles, F. R. Manby, M. Schütz, and others, see http://www .molpro.net

Ziurys, L. M., \& Turner, B. E. 1986, ApJ, 302, L31 
P. P. Bera et al.: Initiating molecular growth in the ISM

\section{Appendix A: Cartesian co-ordinates (Angstrom) of the molecules, ions and complexes - reported here at the MP2/aug-cc-pVTZ level of theory}

$\begin{array}{lr}\mathrm{C} & 1.821632 \\ \mathrm{C} & 1.821621 \\ \mathrm{H} & 1.845675 \\ \mathrm{H} & 1.845642 \\ \mathrm{H} & 1.845653 \\ \mathrm{H} & 1.845621 \\ \mathrm{C} & -1.343793 \\ \mathrm{~N} & -2.487007 \\ \mathrm{H} & -0.236167 \\ \mathrm{H} & -3.497997\end{array}$

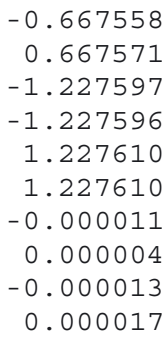

(a)

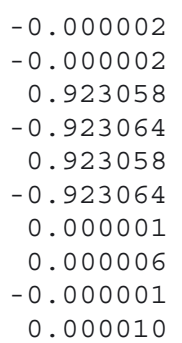

$$
\begin{array}{r}
-1.832972 \\
-1.034346 \\
-2.149544 \\
-2.146968 \\
-0.750420 \\
-0.747555 \\
1.560090 \\
1.553938 \\
1.294328 \\
1.890126 \\
1.283512 \\
1.879811
\end{array}
$$

(a)
$-0.006089$

0.005675

$-0.873898$

0.851707

$-0.922336$

0.944436

0.668301

$-0.667998$

1. 231231

1. 225357

$-1.226324$

$-1.230062$

a)
0.360134

$-0.640147$

0.771513

0.793844

$-1.103210$

$-1.078976$

0.123636

0.125189

1. 005844

$-0.739978$

1. 008903

$-0.736751$
$-0.669484$
0.669491
$-1.228080$
$-1.228080$
1.228087
1. 228087
$-0.000006$
0.000003
$-0.000005$
0.000011
$-0.000001$
$-0.000001$
0.924105
$-0.924108$
0.924104
$-0.924108$
0.000001
0.000004
0.000000
0.000006

(b)

$$
\begin{array}{r}
-0.024579 \\
-0.006830 \\
-0.248140 \\
-0.610224 \\
-0.655950 \\
-0.279836 \\
1.474416 \\
1.505141 \\
2.006570 \\
1.636493 \\
1.758102 \\
2.104833
\end{array}
$$

Fig. A.2. a) $\mathrm{C}_{2} \mathrm{H}_{4}-\mathrm{H}_{2} \mathrm{CNH}_{2}^{+}$. b) $\mathrm{C}_{2} \mathrm{H}_{4}-\mathrm{H}_{2} \mathrm{CNH}_{2}^{+}$.

$$
\begin{array}{rr}
0.416568 & 0.000735 \\
0.962434 & -0.000936 \\
0.825529 & 0.001514 \\
2.015437 & -0.001312 \\
-0.975878 & -0.000525 \\
-0.319184 & 0.000494 \\
-1.509689 & -0.897228 \\
-1.511180 & 0.895227 \\
-0.486499 & -0.886810 \\
-0.485541 & 0.888892
\end{array}
$$

(c)

$$
\begin{array}{r}
-1.606265 \\
-0.511134 \\
-1.579084 \\
-0.390672 \\
0.956340 \\
0.956548 \\
0.619224 \\
1.409884 \\
0.619683 \\
1.410362
\end{array}
$$

$-0.000297$

$-0.000609$

0.000532

$-0.001425$

0.689469

$-0.688681$

1. 245290

1. 242439

$-1.243248$

$-1.242769$

(d)

0.031840

$-0.566022$

1. 050136

$-1.635806$

0. 232450

0.233529

1. 091611

$-0.575725$

1.093597

$-0.573728$

Fig. A.1. a) $\mathrm{C}_{2} \mathrm{H}_{4}-\mathrm{HNCH}^{+}$. b) $\mathrm{C}_{2} \mathrm{H}_{4}-\mathrm{HNCH}^{+}$. c) $\mathrm{C}_{2} \mathrm{H}_{4}-\mathrm{HNCH}^{+}$, Boat. d) $\mathrm{C}_{2} \mathrm{H}_{4}-\mathrm{HNCH}^{+}$, Bridge.

(a)

(b)

$$
\begin{array}{r}
-0.710216 \\
0.809474 \\
-1.091064 \\
-1.170831 \\
1.234749 \\
1.151895 \\
-0.683957 \\
0.764567 \\
-1.449637 \\
-0.780241 \\
0.833179 \\
1.458061
\end{array}
$$

(b)

$$
\begin{array}{rr}
0.102055 & -0.000060 \\
1.204059 & -0.000033 \\
2.346918 & 0.000016 \\
3.358095 & 0.000062 \\
-1.984749 & -1.665896 \\
-1.930523 & -0.605564 \\
-1.930485 & 0.605577 \\
-1.984637 & 1.665913
\end{array}
$$

$-0.003261$

$-0.013020$

$-0.919905$

0.689513

$-0.763127$

0.975434

0.246190

$-0.247890$

$-0.297337$

1. 310745

$-1.297972$

0.320628

0.000000

0.000000

0.000000

0.000000

0.000000

0.000000

0.000000

0.000000

$\begin{array}{lrrr}\mathrm{H} & 0.029411 & -0.000022 & 0.000000 \\ \mathrm{~N} & 1.108403 & -0.000013 & 0.000000 \\ \mathrm{C} & 2.252784 & 0.000021 & 0.000000 \\ \mathrm{H} & 3.326123 & 0.000051 & 0.000000 \\ \mathrm{H} & -1.801320 & 1.668313 & 0.000000 \\ \mathrm{C} & -1.753146 & 0.606104 & 0.000000 \\ \mathrm{C} & -1.753161 & -0.606103 & 0.000000 \\ \mathrm{H} & -1.801367 & -1.668310 & 0.000000\end{array}$

$\begin{array}{rrr}0.059552 & 2.143853 & -0.193378 \\ 0.081387 & 1.074501 & -0.150805 \\ -0.959769 & -0.027623 & -0.113720 \\ -2.035475 & -0.108996 & -0.115604 \\ 2.082098 & -0.035048 & -0.100399 \\ 1.022315 & 0.133537 & -0.109326 \\ -0.089515 & -0.964606 & -0.072634 \\ -0.160594 & -1.973692 & -0.030664\end{array}$

(c)

Fig. A.3. a) $\mathrm{HCCH}-\mathrm{HCNH}+$. b) $\mathrm{HCCH}-\mathrm{HNCH}+$. c) $\mathrm{HCCH}-\mathrm{HCHN}+$, Boat. 
A\&A 535, A74 (2011)

$\begin{array}{lrrr}\mathrm{C} & 1.610675 & -0.396570 & 0.000001 \\ \mathrm{C} & 0.646146 & 0.516073 & 0.000007 \\ \mathrm{H} & 2.635160 & -0.065554 & 0.000000 \\ \mathrm{H} & 1.399440 & -1.453133 & -0.000002 \\ \mathrm{H} & 0.771135 & 1.585118 & 0.000011 \\ \mathrm{C} & -1.791710 & -0.186519 & 0.000008 \\ \mathrm{~N} & -0.681704 & 0.111315 & 0.000009 \\ \mathrm{H} & -2.825769 & -0.469850 & 0.000008\end{array}$

(a)

Fig. A.4. a) $\mathrm{HCN}-\mathrm{C}_{2} \mathrm{H}_{3}^{+}$.

$\begin{array}{rrrr}\mathrm{H} & 2.701646 & -0.384587 & 0.000000 \\ \mathrm{C} & 1.653597 & -0.151740 & 0.000000 \\ \mathrm{~N} & 0.532938 & 0.099795 & 0.000000 \\ \mathrm{H} & -1.117867 & 1.430524 & 0.000000 \\ \mathrm{C} & -0.795361 & 0.393433 & 0.000000 \\ \mathrm{C} & -1.748994 & -0.535074 & 0.000000\end{array}$

(a)

$\begin{array}{rrrr}\mathrm{N} & 0.000000 & -0.000001 & 0.638627 \\ \mathrm{C} & 0.000000 & 0.000000 & 1.793414 \\ \mathrm{H} & 0.000000 & 0.000004 & 2.866479 \\ \mathrm{H} & 0.000000 & 0.000002 & -2.935338 \\ \mathrm{C} & 0.000000 & 0.000000 & -1.868998 \\ \mathrm{C} & 0.000000 & -0.000001 & -0.657650\end{array}$

(b)

$\begin{array}{lr}\mathrm{C} & 1.749134 \\ \mathrm{C} & 1.749514 \\ \mathrm{H} & 1.654941 \\ \mathrm{H} & 1.893808 \\ \mathrm{H} & 1.655631 \\ \mathrm{H} & 1.894499 \\ \mathrm{C} & -1.365952 \\ \mathrm{~N} & -2.221443 \\ \mathrm{H} & -0.263601 \\ \mathrm{H} & -1.619139 \\ \mathrm{H} & -2.438657\end{array}$

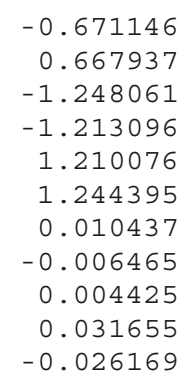

(a)
0.059150
0.084550
0.966755
-0.863327
1.013378
-0.816715
-0.514104
0.340512
-0.222347
-1.575003
1.330147
Fig. A.7. a) $\mathrm{H}_{2} \mathrm{CCH}_{2}-\mathrm{H}_{2} \mathrm{CNH}^{+}$.

$\begin{array}{lrrr}\mathrm{N} & 1.861665 & -0.111737 & 0.000000 \\ \mathrm{C} & 0.681463 & 0.561012 & 0.000000 \\ \mathrm{H} & 2.269921 & -0.448009 & 0.856427 \\ \mathrm{H} & 2.269921 & -0.448009 & -0.856427 \\ \mathrm{H} & 0.508462 & 1.125306 & 0.907168 \\ \mathrm{H} & 0.508462 & 1.125306 & -0.907168 \\ \mathrm{C} & -0.681467 & -0.561016 & 0.000000 \\ \mathrm{~N} & -1.861671 & 0.111729 & 0.000000 \\ \mathrm{H} & -0.508465 & -1.125310 & 0.907168 \\ \mathrm{H} & -0.508465 & -1.125310 & -0.907168 \\ \mathrm{H} & -2.269926 & 0.448005 & 0.856427 \\ \mathrm{H} & -2.269926 & 0.448005 & -0.856427\end{array}$

Fig. A.5. a) $\mathrm{HCCNCH}^{+}$, Branched. b) $\mathrm{HCCNCH}^{+}$, Linear.

$\begin{array}{rrrr}\mathrm{H} & 3.246169 & -0.671240 & 0.000000 \\ \mathrm{C} & 2.229882 & -0.330598 & 0.000000 \\ \mathrm{~N} & 1.131308 & 0.042570 & 0.000000 \\ \mathrm{H} & -3.331501 & -0.712232 & 0.000000 \\ \mathrm{C} & -2.339576 & -0.322177 & 0.000000 \\ \mathrm{C} & -1.179342 & 0.077288 & 0.000000 \\ \mathrm{C} & -0.016409 & 0.755597 & 0.000000\end{array}$

(a)

$\begin{array}{lrrr}\mathrm{N} & 1.097566 & -0.161209 & 0.000000 \\ \mathrm{C} & 2.134106 & 0.335259 & 0.000000 \\ \mathrm{H} & 3.102445 & 0.801476 & 0.000000 \\ \mathrm{H} & -0.148665 & -1.828726 & 0.000000 \\ \mathrm{C} & -0.179470 & -0.747507 & 0.000000 \\ \mathrm{C} & -1.233339 & 0.033527 & 0.000000 \\ \mathrm{C} & -2.307839 & 0.766030 & 0.000000\end{array}$

(b)

Fig. A.6. a) $\mathrm{HCCC}(\mathrm{H}) \mathrm{NC}^{+}$, Branched. b) $\mathrm{HCCCNCH}^{+}$, Linear. (a)

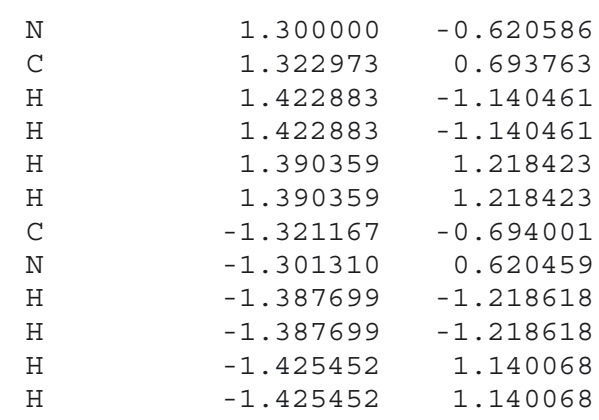

(b)
0.000000

0.000000

0.853444

$-0.853444$

0.935190

$-0.935190$

0.000000

0.000000

0.935297

$-0.935297$

0.853399

$-0.853399$
Fig. A.8. a) $\left[\mathrm{H}_{2} \mathrm{CNH}_{2}\right]_{2}^{+}$. b) $\left[\mathrm{H}_{2} \mathrm{CNH}_{2}\right]_{2}^{+}$. 